\title{
ENSO teleconnections in projections of future climate in ECHAM5/MPI-OM
}

\author{
W. A. Müller · E. Roeckner
}

Received: 30 January 2007 / Accepted: 15 October 2007 / Published online: 1 February 2008

(C) Springer-Verlag 2008

\begin{abstract}
The teleconnections of the El Niño/Southern Oscillation (ENSO) in future climate projections are investigated using results of the coupled climate model ECHAM5/MPI-OM. For this, the IPCC SRES scenario $\mathrm{A} 1 \mathrm{~B}$ and a quadrupled $\mathrm{CO}_{2}$ simulation are considered. It is found that changes of the mean state in the tropical Pacific are likely to condition ENSO teleconnections in the Pacific North America (PNA) region and in the North Atlantic European (NAE) region. With increasing greenhouse gas emissions the changes of the mean states in the tropical and sub-tropical Pacific are El Niño-like in this particular model. Sea surface temperatures in the tropical Pacific are increased predominantly in its eastern part and redistribute the precipitation further eastward. The dynamical response of the atmosphere is such that the equatorial east-west (Walker) circulation and the eastern Pacific inverse Hadley circulation are decreased. Over the subtropical East Pacific and North Atlantic the $200 \mathrm{hPa}$ westerly wind is substantially increased. Composite maps of different climate parameters for positive and negative ENSO events are used to reveal changes of the ENSO teleconnections. Mean sea level pressure and upper tropospheric zonal winds indicate an eastward shift of the well-known teleconnection patterns in the PNA region and an increasing North Atlantic oscillation (NAO) like response over the NAE region. Surface temperature and precipitation underline this effect, particularly over the North Pacific and the central North Atlantic. Moreover, in the NAE region the $200 \mathrm{hPa}$
\end{abstract}

W. A. Müller $(\bowtie) \cdot$ E. Roeckner

Max Planck Institute for Meteorology, Bundestrasse 53,

20146 Hamburg, Germany

e-mail: wolfgang.mueller@zmaw.de westerly wind is increasingly related to the stationary wave activity. Here the stationary waves appear NAO-like.

\section{Introduction}

The El Niño/Southern Oscillation (ENSO) is the largest source of seasonal to inter-annual climate variability in the tropical Pacific as well as in remote regions around the globe. ENSO variability and teleconnections, like many other climate processes, are embedded in the climate change due to the projected increase in greenhouse gas (GHG) emissions. However, it is not clear how ENSO variability and the associated teleconnections might change in the future climate. Based on coupled atmosphere-ocean climate models (CGCM), several studies note changes of the basic statistical properties of ENSO, such as the amplitude and frequency. Some studies suggest an increase in the amplitude (Timmermann et al. 1999, Collins 2000), while other show smaller amplitudes or no changes (Merryfield 2006, Meehl et al. 2006) or suggest strong model dependence (van Oldenborgh et al. 2005; Collins 2005). Moreover, changes in the ENSO frequency are currently not consistently quantified (Guilyardi 2006).

Changes in the climatological mean state in the tropics and extra-tropics are also of vital importance for the ENSO variability and teleconnections. A reduction of the eastwest gradient of the mean sea surface temperature (SST) in the tropical Pacific is closely associated with a reduction of trade winds (e.g. Guilyardi 2006) and ocean upwelling. Furthermore, surface temperatures are likely to condition the onset of deep convection (Gadgil et al. 1984), and changes in mean temperatures in the tropics are directly related to a displacement of the areas of deep convection, 
as seen during ENSO (e.g. Meehl et al. 1993; Hoerling et al. 1997). With respect to increasing GHG emissions, mean temperatures in the tropical Pacific likely show El Niño-like changes (Knutson and Manabe 1995; Meehl et al. 1993; Boer et al. 2000; Collins 2005; Meehl et al. 2006) though some models do not support this (Dai et al. 2001). The uncertainties of the model experiments, however, suggest a broader range of possible future mean states (Collins 2005).

Moreover, the climatological mean state of the extratropical atmosphere has a marked impact on the propagation of tropically forced Rossby waves (Branstator 1984; Trenberth et al. 1998 and reference therein) and can alter the structure of the teleconnections, for instance in the Pacific region. Changes in the ENSO teleconnection in the future climate due to changes in the mid-latitude mean state are shown by Meehl et al. (1993, 2006). They identify a weaker ENSO teleconnection in the mid-latitudes resulting from changes in the mid-latitude mean state, which resembles a wave train similar to the circumpolar wave pattern shown by Branstator (2002), and a reduction of ENSO amplitude. Others, however, stress the model dependence of future changes in the ENSO teleconnection in the atmospheric circulation and indicate that the signal is small compared to the natural variability (Sterl et al. 2007).

The detection of ENSO teleconnection in the North Atlantic/European (NAE) region is complicated by the internal variability of the mid-latitude atmosphere that masks the remote response. However, observational (Fraedrich and Müller 1992; van Oldenborgh et al. 2000; Brönimann et al. 2007) and modelling studies (Merkel and Latif 2002; Mathieu et al. 2004) show evidence of a modest influence of ENSO on the NAE region for various climate parameters in the recent climate. Diagnostic studies referring to the mid-latitude eddy activity (Fraedrich 1994) show distinct variability of the storm track with respect to ENSO (Merkel 2003). They further underline the close correspondence of the North Atlantic mean climate to stationary wave anomalies associated with SST variability in the tropical Pacific but also stress the relative importance of the complex feedback mechanisms between the zonal mean flow and transient and stationary eddies (e.g. DeWeaver and Nigam 2000a, b; Merkel 2003).

Finally, several authors show a direct coherency between the major mode of climate variability in the NAE region, namely the North Atlantic Oscillation (NAO), and diabatic heat sources in the tropical Pacific associated with ENSO (e.g. Lin et al. 2005). In an ensemble of CGCM simulations Müller and Roeckner (2006) could show a significantly increasing relationship between ENSO and the $\mathrm{NAO}$ as a result of future global warming. The present study is an extension of Müller and Roeckner (2006) and investigates why particularly this model shows an increasing impact of ENSO on the NAE climate. We examine how the atmospheric mean state over the tropics and extra-tropics is changed as a result of increasing GHG emissions, and how this affects the remote response to ENSO, particularly in the NAE region.

Section 2 describes the model simulations and the methodology used in this study. In Sect. 3 the current and future mean climate states are investigated. Section 4 examines the impact of ENSO on various climate parameters. Further in this section the relationship between the mean climate and stationary wave activity is investigated. Summary and conclusions are provided in Sect. 5.

\section{Data and methodology}

\subsection{Data}

Monthly means of the Max Planck Institute for Meteorology coupled atmosphere-ocean model ECHAM5/MPIOM (Jungclaus et al. 2006) are used to study the remote response to SST anomalies in the tropical Pacific. The model atmosphere is represented by the latest cycle of the European Centre/Hamburg model version 5 (ECHAM5) and is run at T63L31 resolution (Roeckner et al. 2003). The ocean consists of the Max Planck Institute Ocean Model (MPI-OM) as described in Marsland et al. (2003). Atmosphere and ocean are coupled by means of the OASIS coupler (Valcke et al. 2004) without flux correction.

The undisturbed reference climate is obtained from a 500-year control simulation with GHG concentrations fixed at preindustrial levels and anthropogenic aerosols set to zero (CTRL). The 20th century climate is represented by three model realizations for the period 1900-2000 (20C) forced by observed concentrations of GHG's and precalculated sulfate aerosols. Natural forcings such as changes in solar irradiance and volcanic aerosols are ignored. For the future climate three IPCC SRES A1B stabilization runs for the period 2100-2200 (A1B 22C) are used. Here GHGs and aerosols are fixed at their year 2100 levels. The results of these experiments are compared to those of the 20C simulations.

Furthermore, for testing the robustness of the climate response, an idealized climate change experiment is used with an annual increase of atmospheric $\mathrm{CO}_{2}$ by $1 \%$ until $\mathrm{CO}_{2}$ quadrupling after about 140 simulated years, and stabilization thereafter at the $4 \times \mathrm{CO}_{2}$ level for another 300 years. Only the last 200 years of the stabilization period are used for analysis. The results of this $4 \times \mathrm{CO}_{2}$ experiment are compared to those of the appropriate reference experiment, i.e., the preindustrial control run (CTRL). 


\subsection{Methodology}

In this study ENSO is defined by the monthly mean SST anomalies in the Nino3.4 region $\left(5^{\circ} \mathrm{S}-5^{\circ} \mathrm{N}, 120^{\circ} \mathrm{W}-\right.$ $\left.170^{\circ} \mathrm{W}\right)$. Extra-tropical climate patterns such as the NAO are defined by an EOF analysis of winter mean sea level pressure (MSLP) for the Atlantic region $20-80^{\circ} \mathrm{N}, 100^{\circ} \mathrm{W}-$ $60^{\circ} \mathrm{E}$. Since ENSO/NAO shows the largest variability in boreal winter our investigations are restricted to the winter (DJF) mean.

Given the asymmetric nature of ENSO and the largely asymmetric response of the atmosphere to ENSO (Hoerling et al. 1997) positive and negative composites of several climate parameters are defined with respect to positive and negative ENSO (NAO) events, named hereafter ENSO+ (NAO+) and ENSO- (NAO-), respectively. ENSO+ (ENSO-) is defined as the Nino3.4 index higher (lower) than $1{ }^{\circ} \mathrm{C}\left(-1^{\circ} \mathrm{C}\right)$. This threshold ensures to study the climatic response to relatively strong events with a sufficiently high number of samples. For example, for the $20 \mathrm{C}\left(\mathrm{A} 1 \mathrm{~B} 22 \mathrm{C}, 4 \times \mathrm{CO}_{2}\right.$ ) runs a total amount of $86(100,58)$ positive and $86(106,59)$ negative events are available. Neutral events are those with a Nino3.4 index between -1 and $1^{\circ} \mathrm{C}$. For the NAO the threshold is chosen to be 1 standard deviation (1 SD). For this analysis, all the ensemble members for the considered period are appended giving a total of 300 years for the $20 \mathrm{C}$ and A1B simulations, respectively, and 200 years for the $4 \times \mathrm{CO}_{2}$ simulation (one realization only). The significances of the composites are tested via bootstrap methods.

\section{Changes in the mean state}

Many features in the variability from seasonal to decadal timescales are related to the long-term mean behaviour of the atmosphere. ENSO variability for instance is shown to be associated with the mean state and the seasonal cycle (Guilyardi 2006). But also changes of ENSO teleconnections at the mid-latitudes can be modulated by the changes of the extra-tropical mean state (Meehl et al. 1993). Hence, in this section an overview is given on the time-mean climate changes in the A1B $22 \mathrm{C}$ and $4 \times \mathrm{CO}_{2}$ experiments, respectively. An evaluation of the simulated $20 \mathrm{C}$ climate is beyond the scope of this paper. It has been shown, however, that the model gives a realistic description of ENSO (Jungclaus et al. 2006; van Oldenborgh et al. 2005), tropical intraseasonal variability (Lin et al. 2005), extra-tropical climate (van Ulden and van Oldenborgh 2006), storm tracks (Bengtsson et al. 2006) and Arctic climate (Chapman and Walsh 2007).

\subsection{Temperature and precipitation}

Surface temperature and precipitation are fundamental climate parameters to describe the thermodynamic state of the model. In the Tropics the SST is a manifestation of the upper ocean heat content and an important driver of the atmosphere by modulation of the location and strength of deep convection. Precipitation can be used as a surrogate for diabatic heating. Anomalous heat sources and sinks associated with changes in precipitation give rise to the excitation of Rossby waves and modify the Walker and Hadley circulations.

Figure 1 shows the simulated changes in DJF surface temperature and precipitation together with the respective 20C climatologies. The differences (A1B22C $-20 \mathrm{C}$ ) and $\left(4 \times \mathrm{CO}_{2}-\mathrm{CTRL}\right)$ are shown in Fig. 1c-f. Over the oceans the temperature increase is largest in the tropical regions and in the northwest Pacific. A local heating maximum is found in the tropical eastern Pacific. For A1B $22 \mathrm{C}\left(4 \times \mathrm{CO}_{2}\right)$ the temperature increases by about $3^{\circ} \mathrm{C}$ $\left(5^{\circ} \mathrm{C}\right)$ in the western Pacific and by about $4^{\circ} \mathrm{C}\left(7^{\circ} \mathrm{C}\right)$ in the Nino3 region $(150-90 \mathrm{~W})$, indicating a reduction of the east-west temperature gradient, a feature shared by many climate models (e.g. AchutaRao and Sperber 2006)

The precipitation response shown in Fig. 1d, f reveals more fine-scale structure than that of temperature. In the A1B 22C runs a strong increase in precipitation is found in the central and eastern parts of the equatorial Pacific with maximum values of $3-4 \mathrm{~mm} / \mathrm{day}$. For the $4 \times \mathrm{CO}_{2}$ run this pattern is intensified and maximum values are found in the range of 4-7 mm/day. In the eastern tropical Pacific, on the poleward flanks of the positive anomalies, the precipitation is decreasing in both climate change scenarios. In the tropical Indian Ocean the precipitation is increased by 2-4 mm/day whereas negative anomalies dominate in the tropical Atlantic Ocean. At middle and high latitudes the precipitation tends to increase in both the $\mathrm{A} 1 \mathrm{~B} 22 \mathrm{C}$ and $4 \times \mathrm{CO}_{2}$ runs. Apart from the differences in amplitude, the large scale response patterns of $\mathrm{A} 1 \mathrm{~B} 22 \mathrm{C}$ and $4 \times \mathrm{CO}_{2}$ are remarkably similar.

\subsection{Mean sea level pressure and zonal wind}

We next examine the basic dynamical properties of the model mean state via MSLP and upper level zonal wind. The MSLP has traditionally been used to follow the synoptic weather systems, but also gives a measure of the total atmospheric mass distribution. The zonal wind at $200 \mathrm{hPa}$ (U200) is chosen to show variations in jet streams in the mid-latitudes.

The MSLP for the 20C runs is shown in Fig. 2a. The model reveals the well-known centers of high and low pressure systems in the sub-tropics and in the mid-latitudes, 
(a)

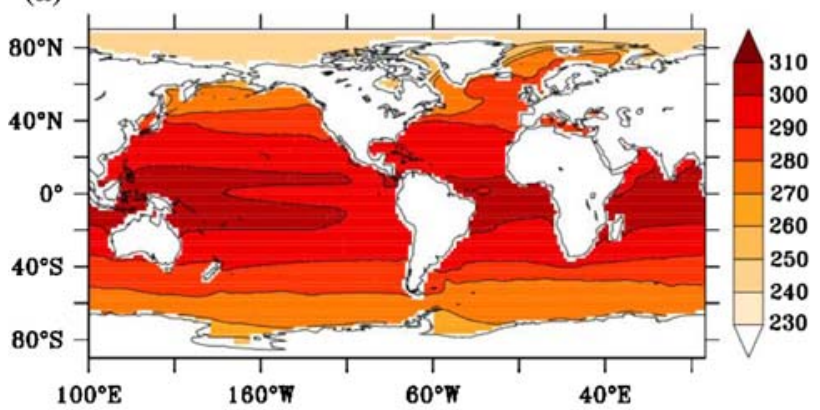

(c)

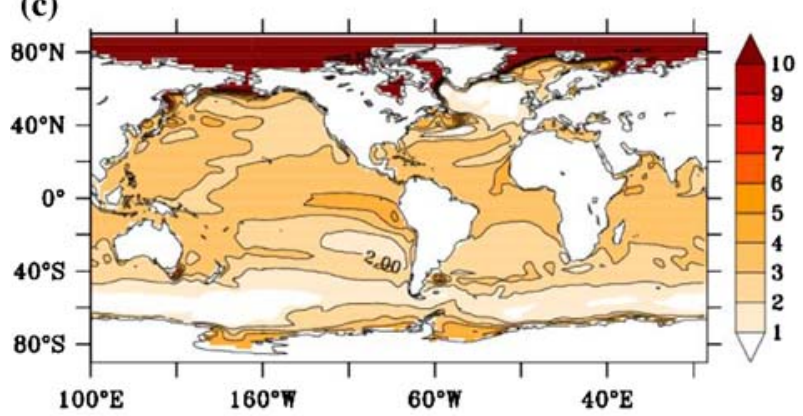

(e)

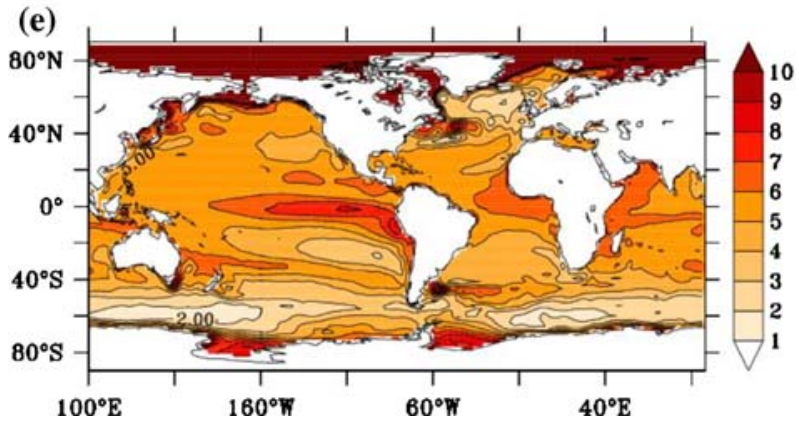

(b)

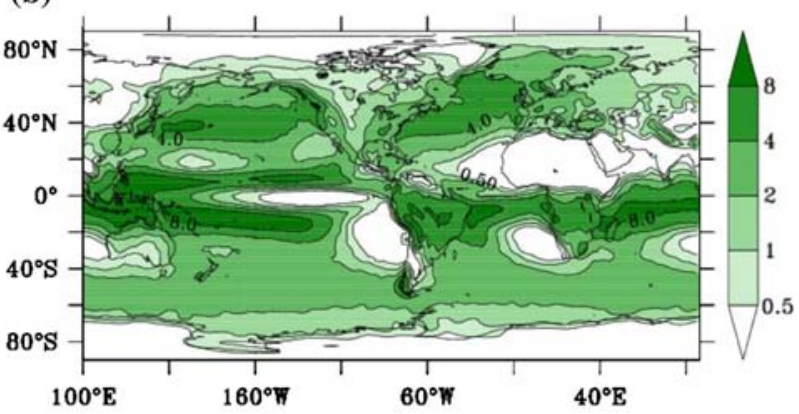

(d)

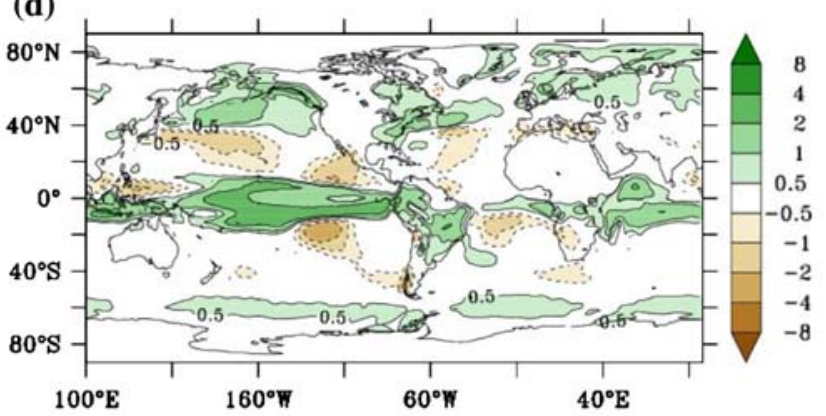

(f)

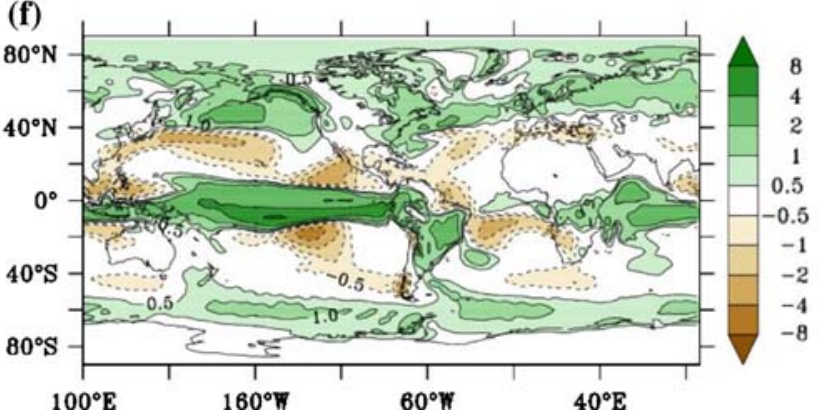

Fig. 1 The winter (DJF) mean surface temperature (left) and precipitation (right) of a, b 20C, c, d A1B 22C $-20 \mathrm{C}$ and e, f $4 \times \mathrm{CO}_{2}-\mathrm{CTRL}$. Units are in $\mathrm{K}$ and $\mathrm{mm} /$ day

respectively. High-pressure systems are found in the descending branch of the Hadley cells in the sub-tropical Atlantic and Northern Africa and in the sub-tropical Pacific. Centers with low pressure are found in higher latitudes of the Pacific and Atlantic region and a low-pressure belt around the coast of Antarctica.

Differences between the model climate and observations (not shown) reveal a positive bias in the northern and southern Pacific and at higher latitudes (up to $5 \mathrm{hPa}$ ), and a negative bias over the North Sea $(-2.5 \mathrm{hPa})$. In general, however, our model is able to capture the observed MSLP distribution with good fidelity (van Ulden and van Oldenborgh 2006).

The differences $(\mathrm{A} 1 \mathrm{~B} 22 \mathrm{C}-20 \mathrm{C})$ and $\left(4 \times \mathrm{CO}_{2}-\right.$ CTRL) are shown in Fig. 2b, c. All simulations show a distinct northward shift of the low pressure in the western North Pacific. In the North Atlantic there is a small pressure decrease in the higher latitudes and an increase over the Mediterranean region. The southern hemisphere response is characterized by a southward shift of the dominant pressure systems.

The distribution of U200 in the 20C runs (Fig 2a) reveals the major storm centers in the northern hemisphere, the Asian Jet and the storm track region in the Atlantic, and the maximum zonal wind around $40-50^{\circ} \mathrm{S}$ in the southern hemisphere. A small region of upper level easterlies is apparent in the tropical West Pacific.

The differences of winter means (A1B 22C - 20C) and $\left(4 \times \mathrm{CO}_{2}-\mathrm{CTRL}\right.$ ) (Fig. 2b, c) show marked westerly wind anomalies in the western North Pacific and in the 40$50^{\circ} \mathrm{S}$ belt, the latter associated with a poleward shift of the maximum wind zones. Moreover, in the tropical to subtropical Pacific region an increase of easterly winds along the equator is flanked by increased westerlies in the sub- 

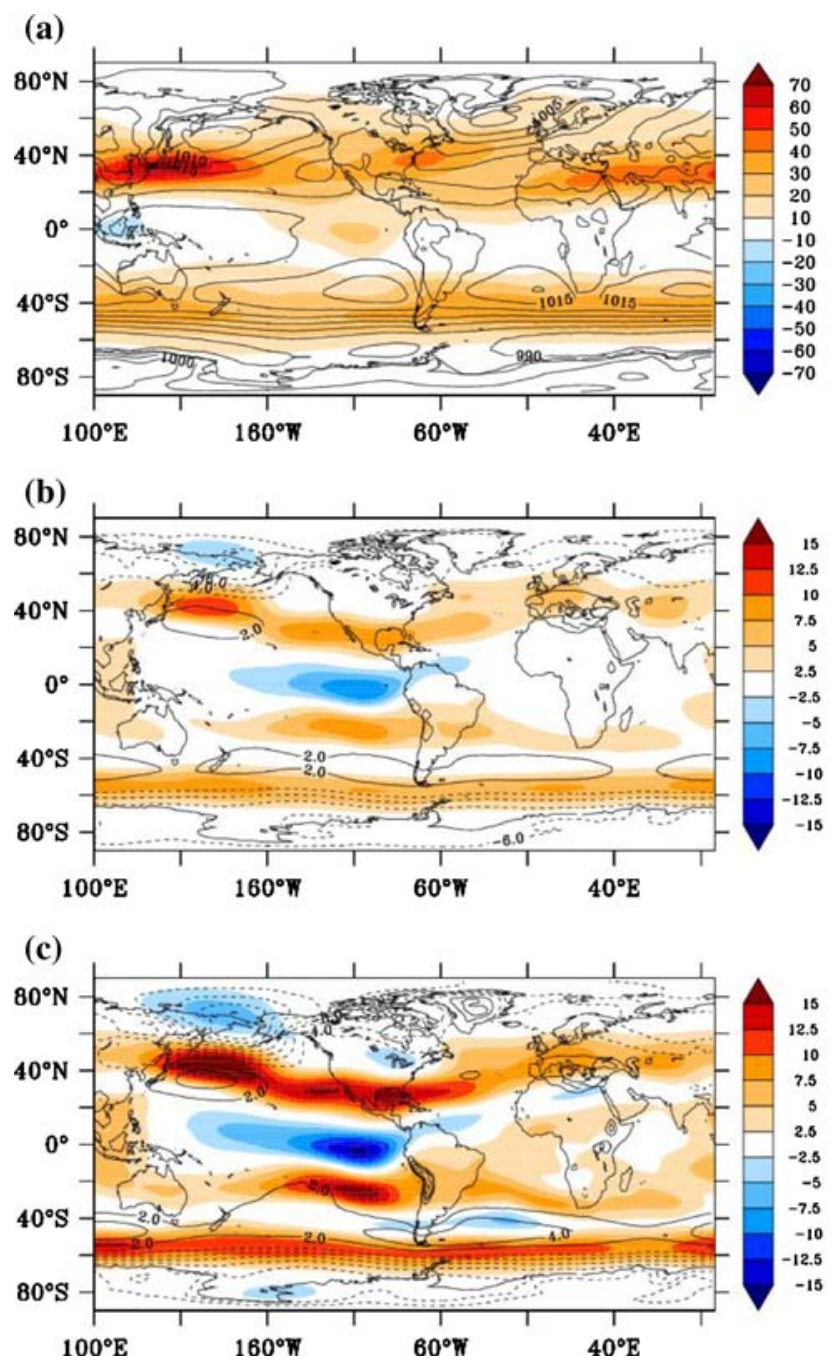

Fig. 2 Same as Fig. 1 but for (shadings) zonal wind at $200 \mathrm{hPa}$ and (contours) mean sea level pressure $(M S L P)$. Contour intervals are a $10 \mathrm{~m} / \mathrm{s}$ and $\mathbf{c}, \mathbf{e} 2.5 \mathrm{~m} / \mathrm{s}$ for the zonal wind and b $5 \mathrm{hPa}$ and d, f $2 \mathrm{hPa}$ for the MSLP

tropics. The westerly wind anomalies in the sub-tropics are elongated into the subtropical North Atlantic region. This response is shared by many IPCC AR4 simulations as recently shown by Meehl and Teng (2007). For the A1B $22 \mathrm{C}\left(4 \times \mathrm{CO}_{2}\right)$ runs the differences exceed values of about $-7.5(-10) \mathrm{m} / \mathrm{s}$ and $7.5(15) \mathrm{m} / \mathrm{s}$ in the equatorial and northern sub-tropical region, respectively.

As has been shown in Figs. 1 and 2 the anomalous diabatic heating in the tropical eastern Pacific is in close correspondence with changes in the zonal upper level equatorial easterlies and the subtropical jets. The linkage between these patterns can be attributed to changes in the tropical circulation such as a reduced Pacific Walker circulation and an anomalous East Pacific Hadley circulation that is also found during El Niño events (e. g. Wang 2005). During the mature phase of El Niño an anomalous Walker circulation forms with air rising over the anomalous warming in the eastern equatorial Pacific and westward flow aloft. In the western Pacific the air sinks and turns back to the eastern Pacific in the lower troposphere as a westerly wind anomaly. Further an anomalous Hadley circulation appears in the eastern Pacific with rising and descending air in the tropical and subtropical regions, respectively.

To confirm this for the changes in the mean fields, Fig. 3 shows the simulated distribution of the zonal and vertical wind components along the equator (left panels) as well as the meridional and vertical wind components in the East Pacific (right panels). The $20 \mathrm{C}$ runs show the Walker circulation in the tropical Pacific with rising air over the Indonesian region and sinking air in the central to eastern Pacific, and associated easterlies in the lower troposphere and westerlies in the upper troposphere (Fig. 3a). Further over the continental heat sources in the Amazon region and tropical Africa upward motions occur in the lower and middle troposphere. The tropical Atlantic Walker cell is closed by lower level easterlies and upper level westerly winds.

For the $\mathrm{A} 1 \mathrm{~B} 22 \mathrm{C}$ and $4 \times \mathrm{CO}_{2}$ runs the general structure of the circulation does not change. However, over the central to eastern Pacific the decreasing descent and weaker easterlies at the surface are associated with weaker westerlies aloft (Fig. 3c, e) indicating a reduction in the strength of the Walker circulation (as seen in many climate models of the IPCC AR4; Vecchi and Soden 2007). Over the tropical Atlantic region a small increase in zonal wind at about $300 \mathrm{hPa}$ is found.

The eastern Pacific Hadley circulation is illustrated by the zonal mean vertical and meridional wind. For the 20C runs (Fig. 3b) descending (ascending) air at the equator $\left(10^{\circ}\right.$ poleward off the equator) and associated upper and lower level equatorward and poleward winds form an inverse Hadley circulation. The differences between the $20 \mathrm{C}$ run and the $\mathrm{A} 1 \mathrm{~B}$ and $4 \times \mathrm{CO}_{2}$ runs show an anomalous Hadley circulation (Fig. 3d, f) characterized by rising air around the equator (stronger in the southern branch of the ITCZ) and anomalous upper level poleward motion at about $200 \mathrm{hPa}$ with values of about 1 and $3 \mathrm{~m} / \mathrm{s}$ for the $\mathrm{A} 1 \mathrm{~B} 22 \mathrm{C}$ and $4 \times \mathrm{CO}_{2}$ runs, respectively.

As has been stated in the introduction, extra-tropical teleconnections associated with SST variability in the tropics critically depend on the mean state of the tropics and extra-tropics and on the diabatic forcing from the tropical region. Therefore changes in the mean states, as shown in this section, may alter ENSO teleconnections in the midlatitudes. In the next section we examine how ENSO teleconnections are modulated by the changes of the mean states in the future climate. 

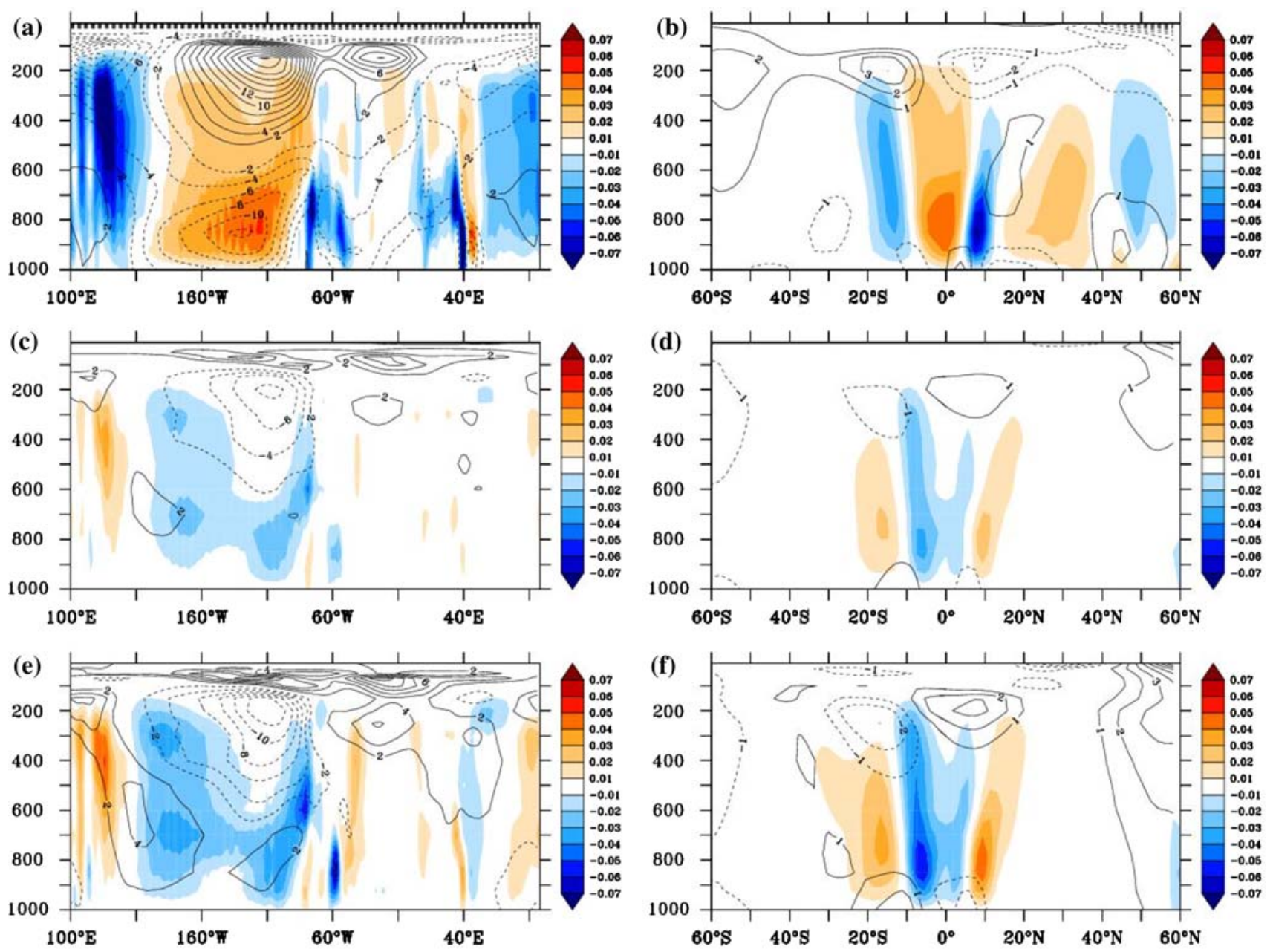

Fig. 3 Winter (DJF) mean meridionally averaged zonal and vertical wind for a $20 \mathrm{C}$, c $\mathrm{A} 1 \mathrm{~B} 22 \mathrm{C}-20 \mathrm{C}$ and (e) $4 \times \mathrm{CO}_{2}-\mathrm{CTRL}$. Values are averaged for $2.5^{\circ} \mathrm{N}-2.5^{\circ} \mathrm{S}$. Contour interval are $2 \mathrm{~m} / \mathrm{s}$ and shadings $0.01 \mathrm{~Pa} / \mathrm{s}$. Further winter mean of zonally averaged

meridional and vertical wind for the eastern Pacific $\left(150-100^{\circ} \mathrm{W}\right)$ for b 20C, d A1B-CTRL and e $4 \times \mathrm{CO}_{2}-$ CTRL. Contour intervals are $1 \mathrm{~m} / \mathrm{s}$ and shadings $0.01 \mathrm{~Pa} / \mathrm{s}$

\section{ENSO variability and teleconnections}

\subsection{ENSO variability in current and future climate}

Figure 4 shows time series of the Nino3.4 index of single ensemble members and the power spectra when all ensemble members are appended. For 20C (Fig. 4a) alternating peaks of El Niño and La Niña events occur with frequent multi-annual interruptions. The power spectrum (Fig. 4c) identifies the well-known broadband spectrum of 2-8 year. As pointed out by Jungclaus et al. (2006) the simulated interannual variability in the tropical Pacific (associated with ENSO) is roughly $0.5^{\circ} \mathrm{K}$ higher than in observations. The seasonal cycle is improved related to earlier version of the model (Keenlyside et al. 2004) and is characterized by a weak semiannual cycle in the west and westward propagating annual cycle in the east (Fig. 12a,b

in Jungclaus et al. 2006). Moreover, model analysis show that the nonlinearity of ENSO (i.e. defined by the higher moments of the SST anomalies) is significantly underestimated. This is of importance since it is suggested that in models with a large degree of non-linearity (e.g. non-zero skewness in tropical Pacific SST) the mean state can act on ENSO activity (Yeh and Kirtman 2007). In general model intercomparison certify for ECHAM5/MPI-OM a "larger to much larger-than-observed" variability of ENSO and comparable tropical Pacific mean state and seasonal cycle (Guilyardi 2006)

For the A1B 22C (Fig. 4b) and $4 \times \mathrm{CO}_{2}$ (not shown) runs the time series show quasi-periodic signals with larger amplitudes than in the $20 \mathrm{C}$ runs. Moreover the peak in the 3-4year frequency band is more pronounced than in the 20C simulations. The basic proporties of ENSO defined by the first statistical moments reveal an 

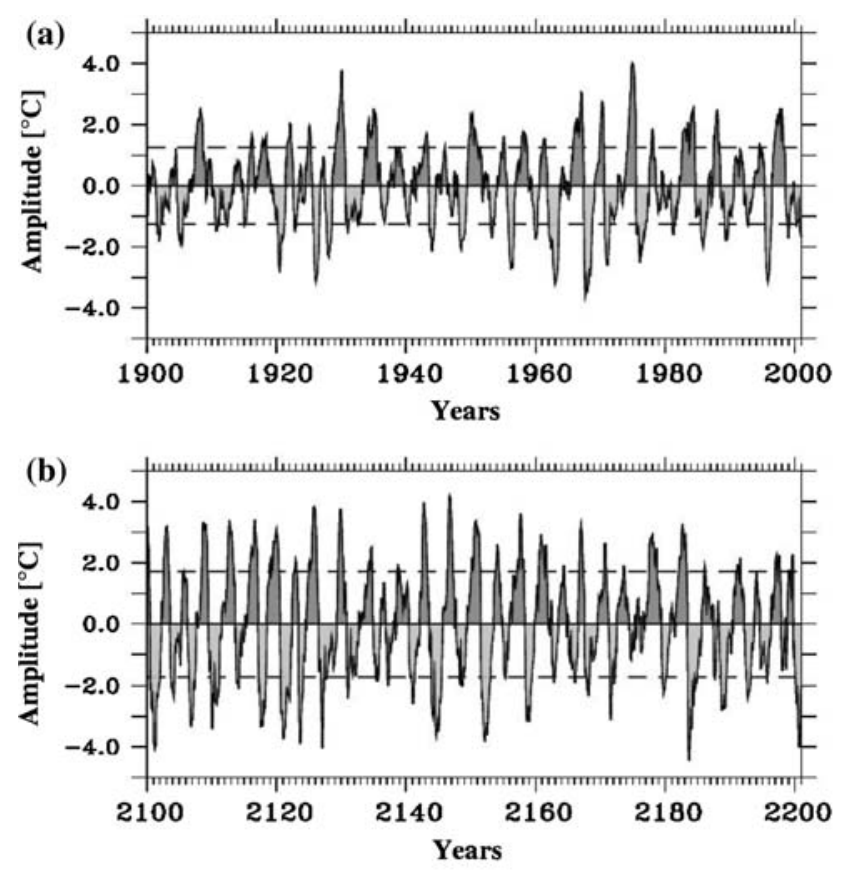

(c)

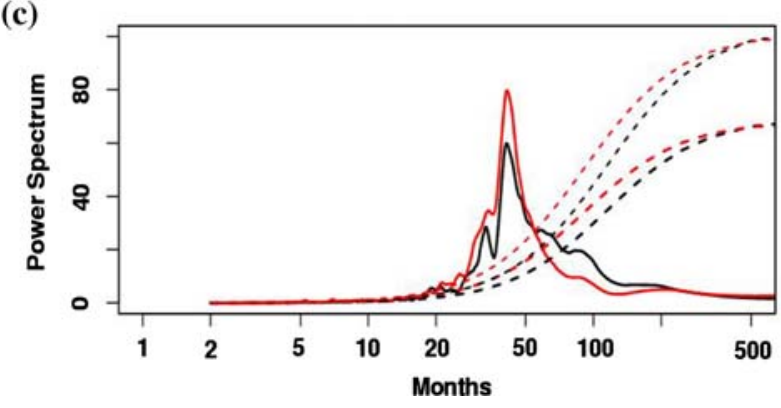

Fig. 4 Time series of monthly SST anomalies of the Nino3.4 region of a single member of $\mathbf{a} 20 \mathrm{C}$ and $\mathbf{b} \mathrm{A} 1 \mathrm{~B} 22 \mathrm{C}$ and $\mathbf{c}$ power spectrum of 20C (black) and A1B 22C (red) for all members appended. Dashed lines in the time series indicate 1 standard deviation of the entire period. Dashed line in the power spectrum indicate fitted AR(1) processes (thick) and the rejection limit $(\alpha=0.05)$ for frequencies significantly larger than the background spectrum [AR(1)]

increase in ENSO variability with increasing GHG concentrations (see also van Oldenborgh et al. 2005, Müller and Roeckner 2006) but no indication of nonlinearity (i.e. near zero skewness).

Despite the relatively consistent response of the tropical Pacific mean SST to increased GHG concentrations changes of the basic properties of ENSO show a large spread among the climate models (i.e. van Oldenborgh et al. 2005; Guilyardi 2006). In the climate models contributing to the IPCC AR4 ECHAM5/MPI-OM is among those models with the largest increase of ENSO amplitude in the future climate projections. Some authors (Philip and van Oldenborgh 2006) could show that the feedback processes between SST, wind stress and the thermocline are affected by the changes in the mean state and this may reflect on the basic properties of ENSO. Other factors such as the nonlinearity of ENSO (see also Yeh and Kirtman 2007) may also provide a key mechanism for explaining the ENSO variability in a changing environment. This issue, however, is not further discussed here, but will be reported elsewhere.

\subsection{Temperature and precipitation}

Composite maps of surface temperature and total precipitation for the 20C runs are shown in Figs. 5a, b and $6 a, b$, respectively. For ENSO+ the figure reveals the characteristic temperature distribution in the tropical Pacific region, particularly in the central and eastern part with an increase of about $2-3^{\circ} \mathrm{C}$. These values are approximately $1{ }^{\circ} \mathrm{C}$ higher than in observations and strongly shifted to the West (the latter shared by many model runs of the IPCC AR4, e.g. Meehl and Teng 2007). Positive temperature anomalies are further found in northeastern Brazil, Australia and Canada/ Alaska and lower temperatures in the tropical West, in the extratropical Northwest Pacific and in the southeastern US, (close to the observations, see Fig. 3 in Meehl and Teng 2007). Stronger rainfall appears predominantly over the western part of the Indian Ocean and the equatorial Pacific. Consistent with the temperature anomalies the heavy rainfall anomaly in the central Pacific is biased to the West. Weaker rainfall is simulated in the equatorial West Pacific and subtropical Pacific, Northern Australia and the eastern Indian Ocean, the equatorial Atlantic and Northeast Brazil (Fig. 6a). Composite maps for ENSO- (Fig. 6b) show largely similar patterns with reversed signs. Regional differences, for example over the North American continent, are largely related to the nonlinearity of the ENSO teleconnections (Hoerling et al. 1997). Note that despite the realistic simulation of the gross ENSO teleconnection patterns regional differences occur within the ensemble of IPCC AR4 runs associated with the model dependent simulation of the ENSO amplitude (for details see e.g. Meehl and Teng 2007).

The differences of the ENSO+ anomalies (A1B 22C 20C) and $\left(4 \times \mathrm{CO}_{2}-\mathrm{CTRL}\right)$ (Figs. $\left.5 \mathrm{c}, \mathrm{e}, 6 \mathrm{c}, \mathrm{e}\right)$ reveal changes in both the tropical and extra-tropical regions. In the tropical Pacific the figure shows an increase (decrease) of precipitation approximately east (west) of the dateline, indicating an eastward displacement of the maximum diabatic heating. Over other topical regions, such as South America, Indonesia and Africa, the El Niño signature is intensified. In the subtropical Pacific (at around $150^{\circ} \mathrm{W}$ ) negative precipitation anomalies emerge further northeastward. Over the subtropical North Atlantic precipitation anomalies are significantly increased and also shifted eastward. Over the landmasses bordering the extra-tropical North Pacific the temperature anomalies changes are 
(a)

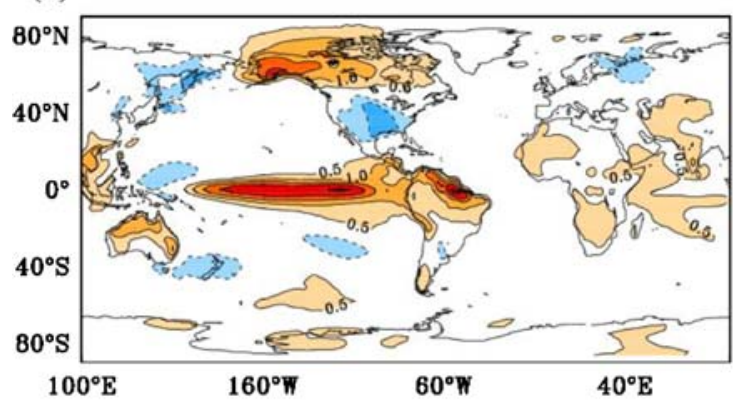

(c)

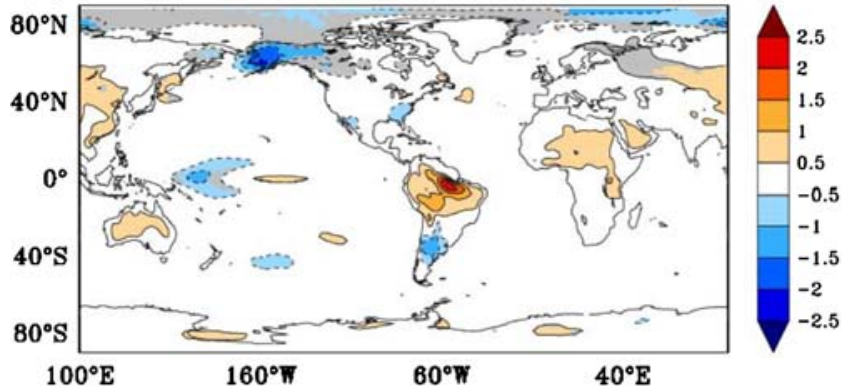

(e)

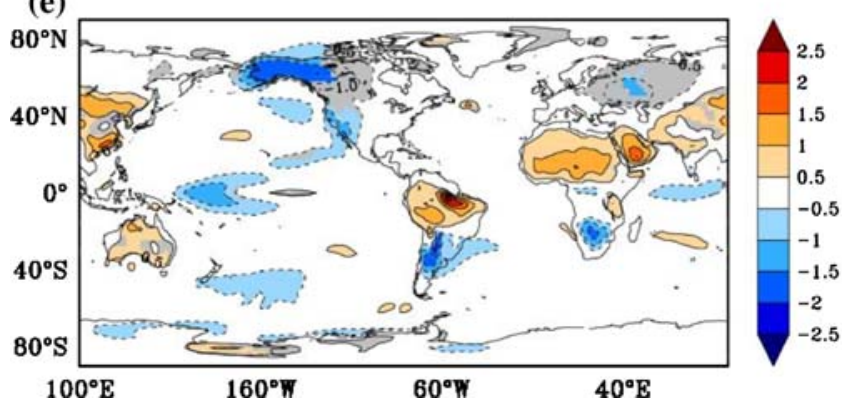

Fig. 5 Composite maps of surface temperature for DJF for (left) ENSO+ - NEUTRAL and (right) ENSO- - NEUTRAL. Shown are a, b $20 \mathrm{C}$, c, d A1B $22 \mathrm{C}-20 \mathrm{C}$ and e, f $4 \times \mathrm{CO}_{2}-\mathrm{CTRL}$.

negative particularly over Alaska (indicative for a reduced El Niño influence) and positive over eastern Asia at around $40^{\circ} \mathrm{N}$, respectively. For ENSO- (Figs. 5d, f, 6d, f) the composite maps (particularly of the precipitation) show generally an intensification of the La Niña signature throughout the Tropics. Precipitation anomalies in the subtropical North Pacific and North Atlantic (at around $30^{\circ} \mathrm{N}$ ) also appear shifted eastward. In the extra-tropics positive and negative temperature anomalies changes are found over the Aleutians and northeastern America, respectively.

\subsection{MSLP and U200}

Next we show the composite maps of MSLP and U200 for the 20C, A1B and $4 \times \mathrm{CO}_{2}$ runs (Fig. 7). For ENSO+ in 20C (Fig. 7a) positive (negative) zonal wind anomalies are (b)

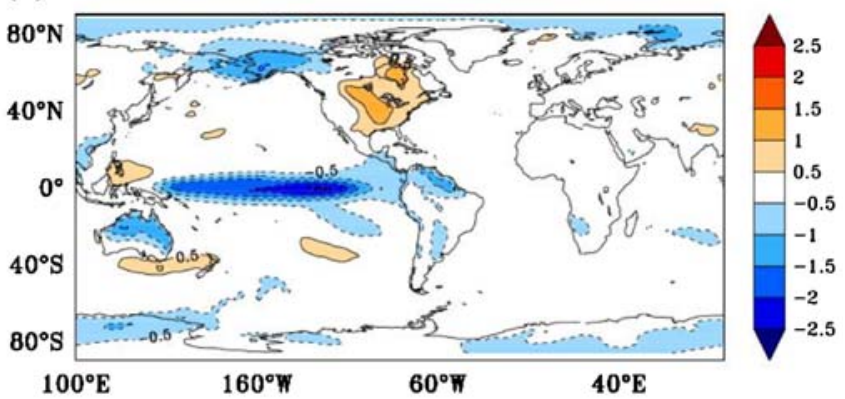

(d)

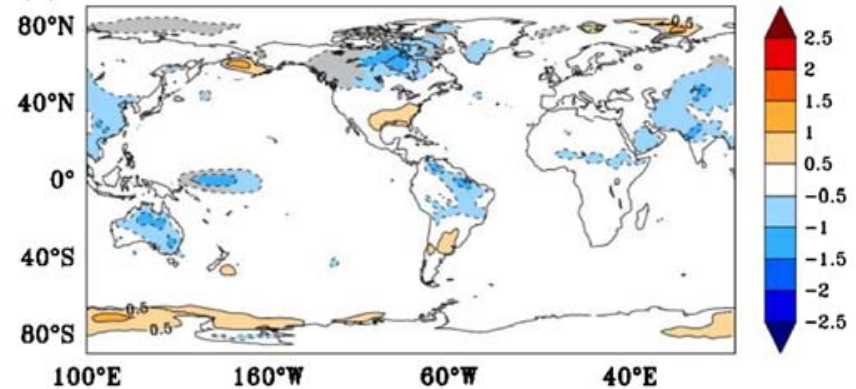

(f)

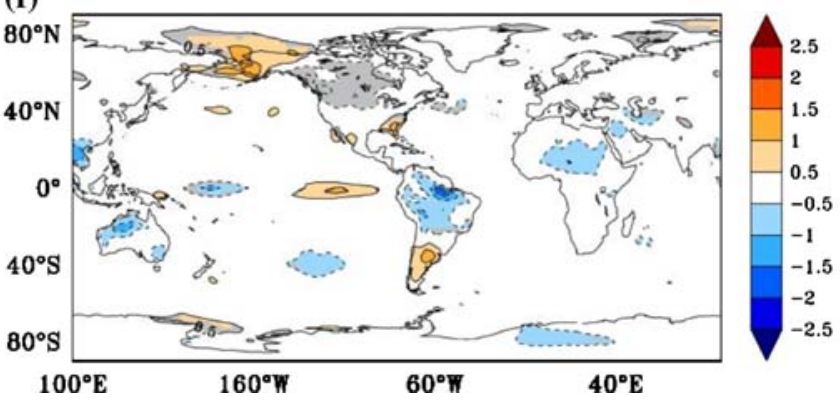

Values exceeding 95\% significance level are shown in colours. The significance is tested via bootstrap method

found in the subtropical (tropical) eastern Pacific. MSLP is lower in the eastern tropical Pacific and higher in the western tropical Pacific, indicating the Southern Oscillation part of ENSO. In the North Pacific the pressure distribution shows a deepening of the Aleutian low. Negative MSLP anomalies are also found over the southeast US region. Generally these patterns are consistent with results found in observations (e.g. Manzini et al. 2006) and also in many model runs in the IPCC AR4 (e.g. Mehl and Teng 2007). For ENSO- (Fig. 7b) the zonal wind response also shows alternating pattern of easterlies and westerlies similar to ENSO+ but with reversed signs and shifted westward by about $30-40^{\circ}$. Further the MSLP pattern in the North Pacific reveals a weakening of the Aleutian low.

The differences (A1B 22C - 20C) and $\left(4 \times \mathrm{CO}_{2}-\right.$ CTRL) for ENSO+ and ENSO- are shown in Fig. 7c-f. For ENSO+ the difference maps reveal a northeastward shift, compared to ENSO+ in 20C, of both U200 and MSLP 
(a)

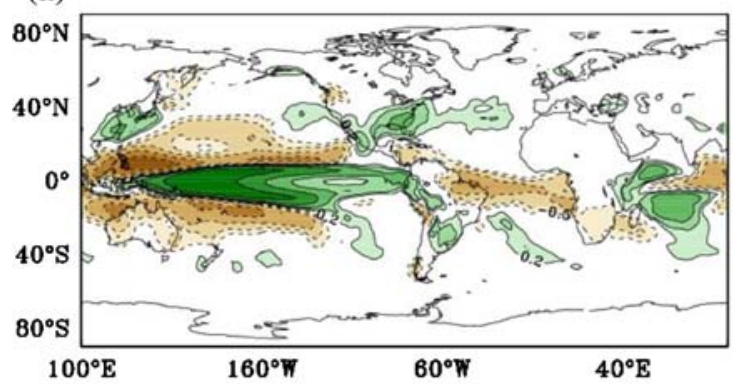

(c)

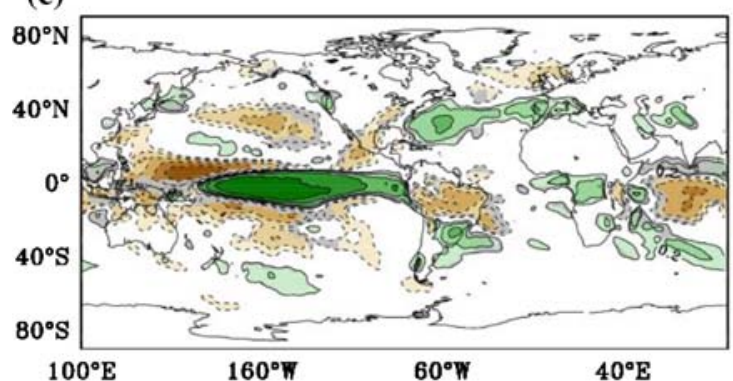

(e)
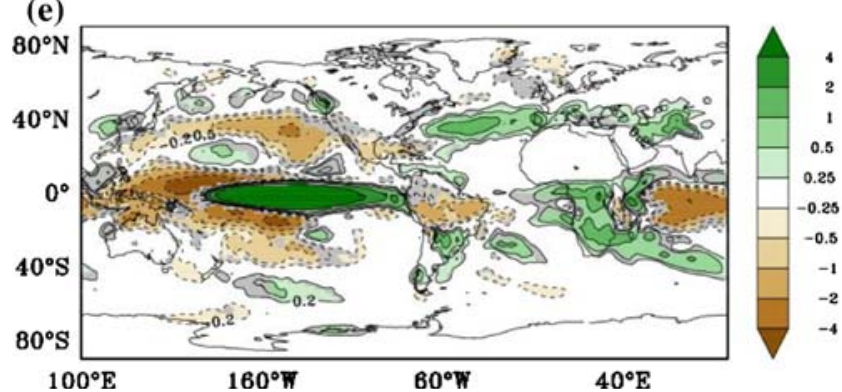

Fig. 6 Same as Fig. 5 but for precipitation

in the North Pacific. Over the North Atlantic the distribution of the MSLP resembles the negative phase of the NAO with a weaking of the meridional pressure gradients of about 2 and $3 \mathrm{hPa}$ for $\mathrm{A} 1 \mathrm{~B} 22 \mathrm{C}$ and $4 \times \mathrm{CO}_{2}$, respectively. Here the changes of the zonal wind anomalies amount up to $5 \mathrm{~m} / \mathrm{s}$ for the A1B $22 \mathrm{C}$ and $4 \times \mathrm{CO}_{2}$ runs. For ENSO- the MSLP and U200 pattern associated with the weakening of the Aleutian Low appears shifted to the east, but their magnitudes are considerably smaller than for ENSO+.

The composite maps of the NEUTRAL cases of the illustrated climate parameters (Fig. 8) resemble the mean states and their response patterns (Figs. 1,2). This indicates that the El Niño-like changes in the time-mean climate are not caused by changes in the frequency distribution of ENSO events, consistent with the fact that the magnitude of the El Niño-like response in the mean state of SST, precipitation, MSLP and U200 is much larger than the respective changes in ENSO+ (cf., Figs. 5c, e, 6c, e, 7c, e).

The composite maps of ENSO+ and ENSO- in the future climate of ECHAM5/MPI-OM (Fig. 7c-f) reveal a substantial shift, compared to 20C (Fig. 7a, b), in the (b)

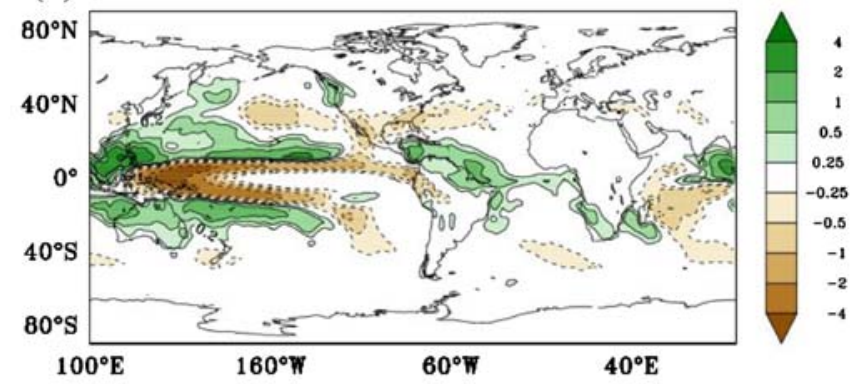

(d)
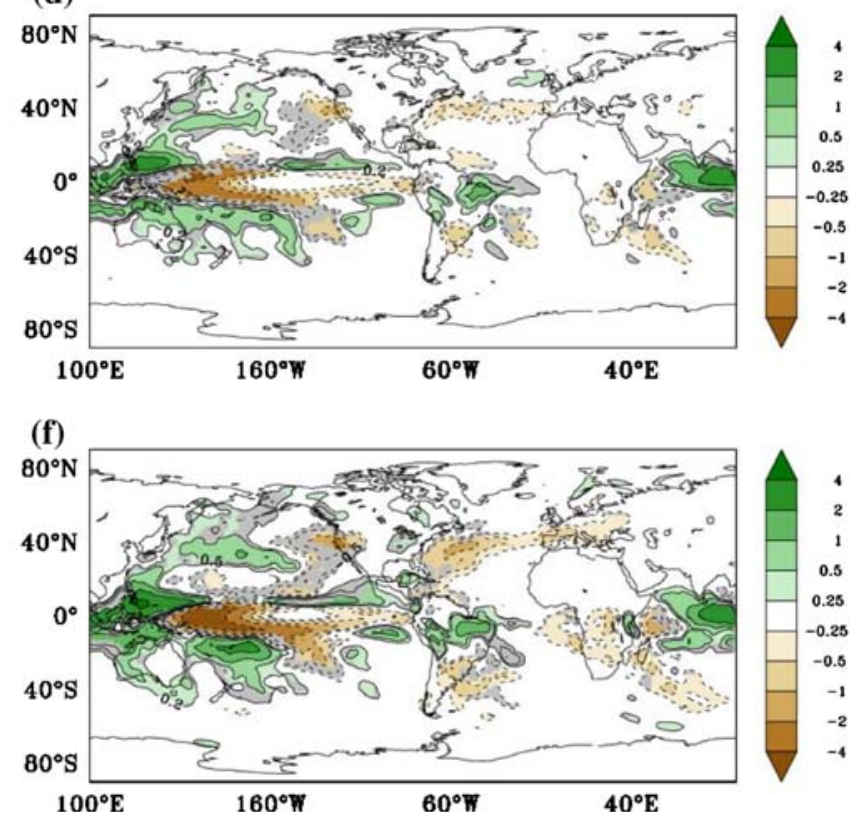

extra-tropical teleconnection patterns, in the PNA but also in the NAE region. Here the composites of ENSO+ show a pronounced zonal elongation of MSLP and U200. Variations in the zonal mean zonal wind, however, are of importance for the propagation of tropospheric stationary waves (e.g. Branstator 1984; Nigam and Lindzen 1989; Hoerling and Kumar 1995; Ting et al. 1996). Moreover, there is evidence of a positive feedback between zonal wind and stationary wave anomalies (DeWeaver and Nigam 2000a, b). Whereas for the PNA region stationary waves are strongly affected by the teleconnections associated with tropical SST variability, the zonal flow/ stationary waves interactions in the NAE region appear more or less due to the variations in the mid-latitude zonal wind anomalies (Ting et al. 1996) and is suggested to be insensitive to SST variability such as ENSO (Hoerling and Kumar 1995). However, as shown in the previous section the westerly wind increases in the NAE subtropical jet region in the future climate, as a result of the latent heat release in the tropics. Hence in this context we next examine how the stationary waves in the NAE region are 
(a)

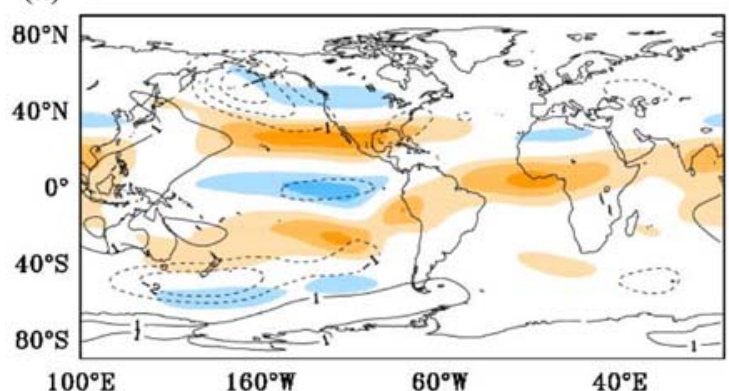

(c)

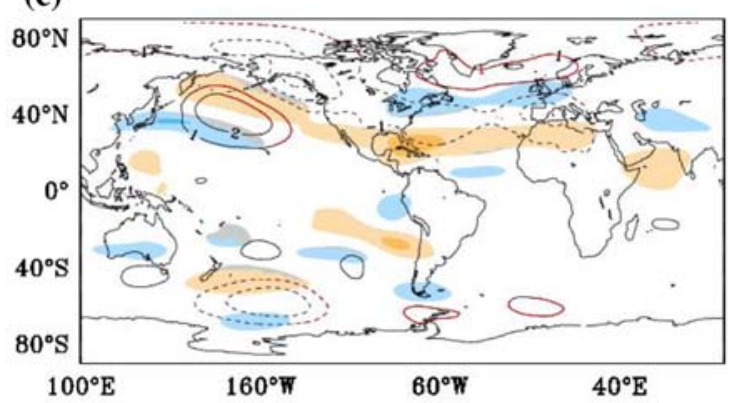

(e)

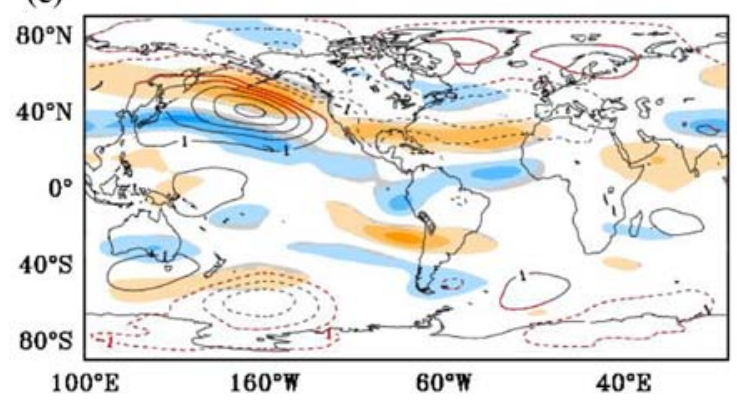

(b)

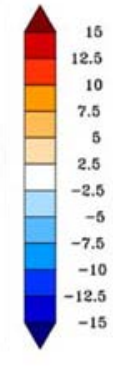

$80^{\circ} \mathrm{N}$
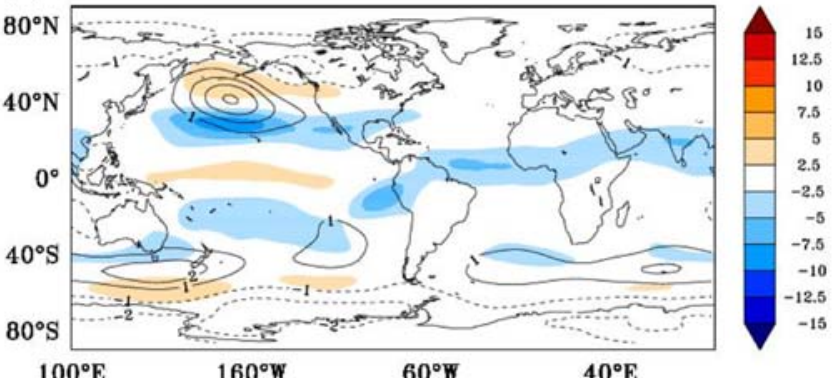

(d)

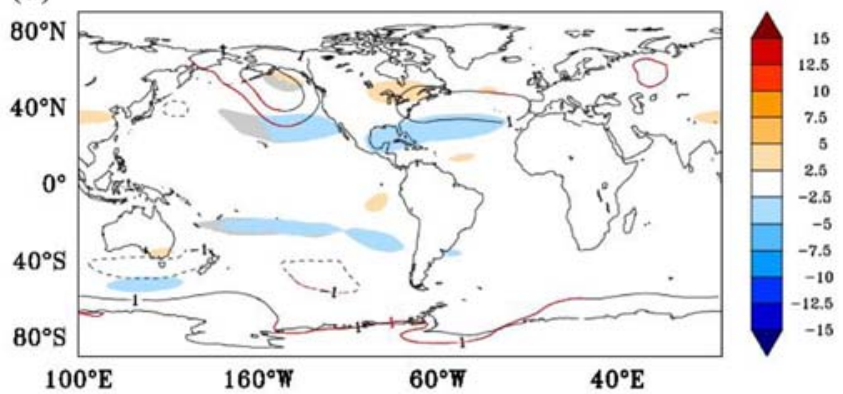

(f)

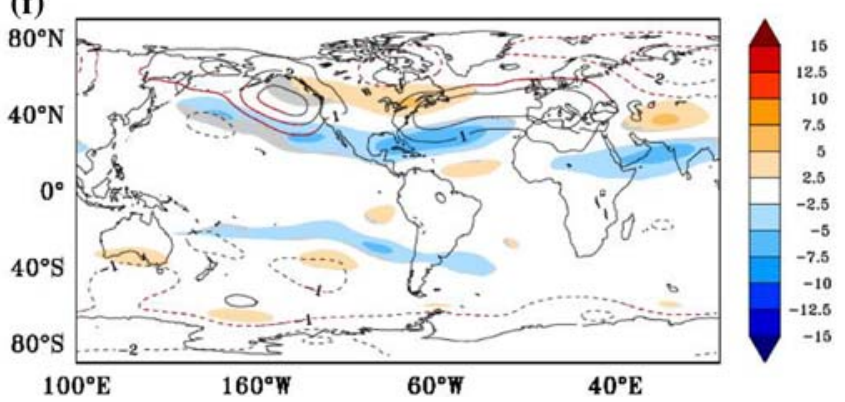

Fig. 7 Same as Fig. 5 but for U200 (shadings) and MSLP (contours). Contour intervals are $1 \mathrm{hPa}$ and shadings $2.5 \mathrm{~m} / \mathrm{s}$. Values exceeding $95 \%$ significance are shown in colors

affected by zonal wind anomalies during recent and future climate conditions.

\subsection{Stationary wave activity}

Firstly, we underline the relationship between the zonal wind in the NAE region and ENSO variability shown by scatter plots of a zonal wind index (UI) for the 20C, A1B 22C (Fig. 9a) and CTRL, $4 \times \mathrm{CO}_{2}$ runs (Fig. 9c). Here, the UI is defined as the difference of the zonal wind anomalies at $200 \mathrm{hPa}$ between the mid-latitudes (50-60 N) and sub-tropics $(30-40 \mathrm{~N})$ in the NAE region. Despite the large variability the scatter plots indicate that the UI over the North Atlantic is increasingly affected by ENSO for higher GHG concentrations. For larger ENSO+ events the UI is likely found to be negative associated with stronger (weaker) westerlies over the subtropical (mid-latitude) North Atlantic. For negative ENSO events the UI is more likely positive. The correlation between the UI index and the Nino3.4 index for the individual ensemble members is significantly increased from $-0.21 \leq r \leq-0.07$ in the $20 \mathrm{C}$ runs to $-0.56 \leq r \leq-0.49(r=-0.53)$ in the $\mathrm{A} 1 \mathrm{~B}$ $22 \mathrm{C}\left(4 \times \mathrm{CO}_{2}\right)$ runs.

Figure $9 \mathrm{~b}$ shows composites of the UI for different magnitudes of the Nino3.4 anomalies for 20C and A1B $22 \mathrm{C}$. Here the composite of the UI for each Nino3.4 amplitude is obtained by averaging all UI that are found in a $1.5^{\circ} \mathrm{C}$ bin of ENSO amplitudes (for example, for a Nino3.4 amplitude of $1.75^{\circ} \mathrm{C}$ we consider those UI that can be found when the Nino3.4 index is between 1.0 and $2.5^{\circ} \mathrm{C}$ ). Note, however, that the results do not crucially depend on the bin size. As can be seen from the figure the composites of the UI for fixed ENSO amplitudes are larger for the A1B 22C runs that for the 20C runs. Moreover, in A1B 22C the relationship between ENSO and the UI is hardly significant below $1^{\circ} \mathrm{C}$, but for stronger ENSO amplitudes the relationship becomes significantly different 

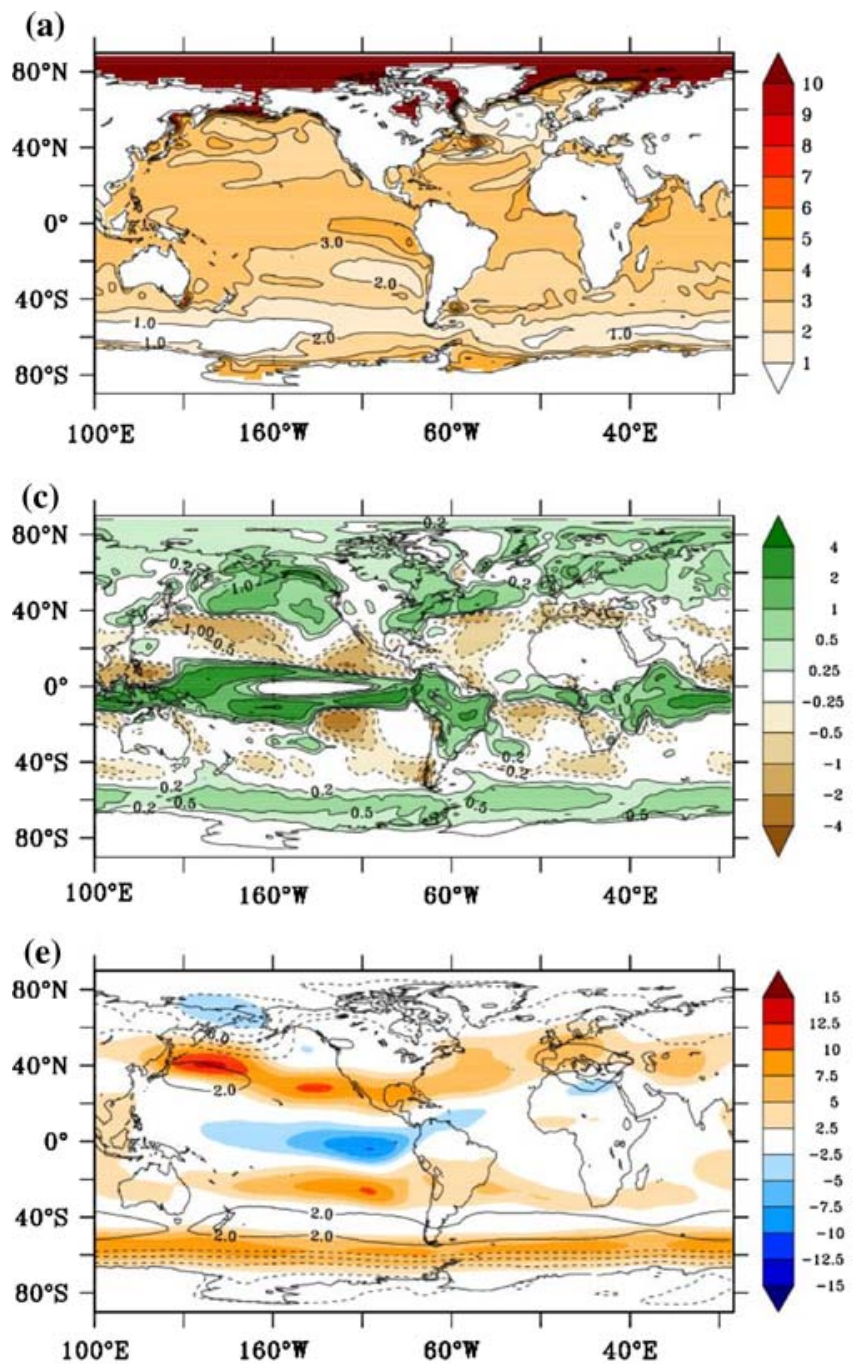
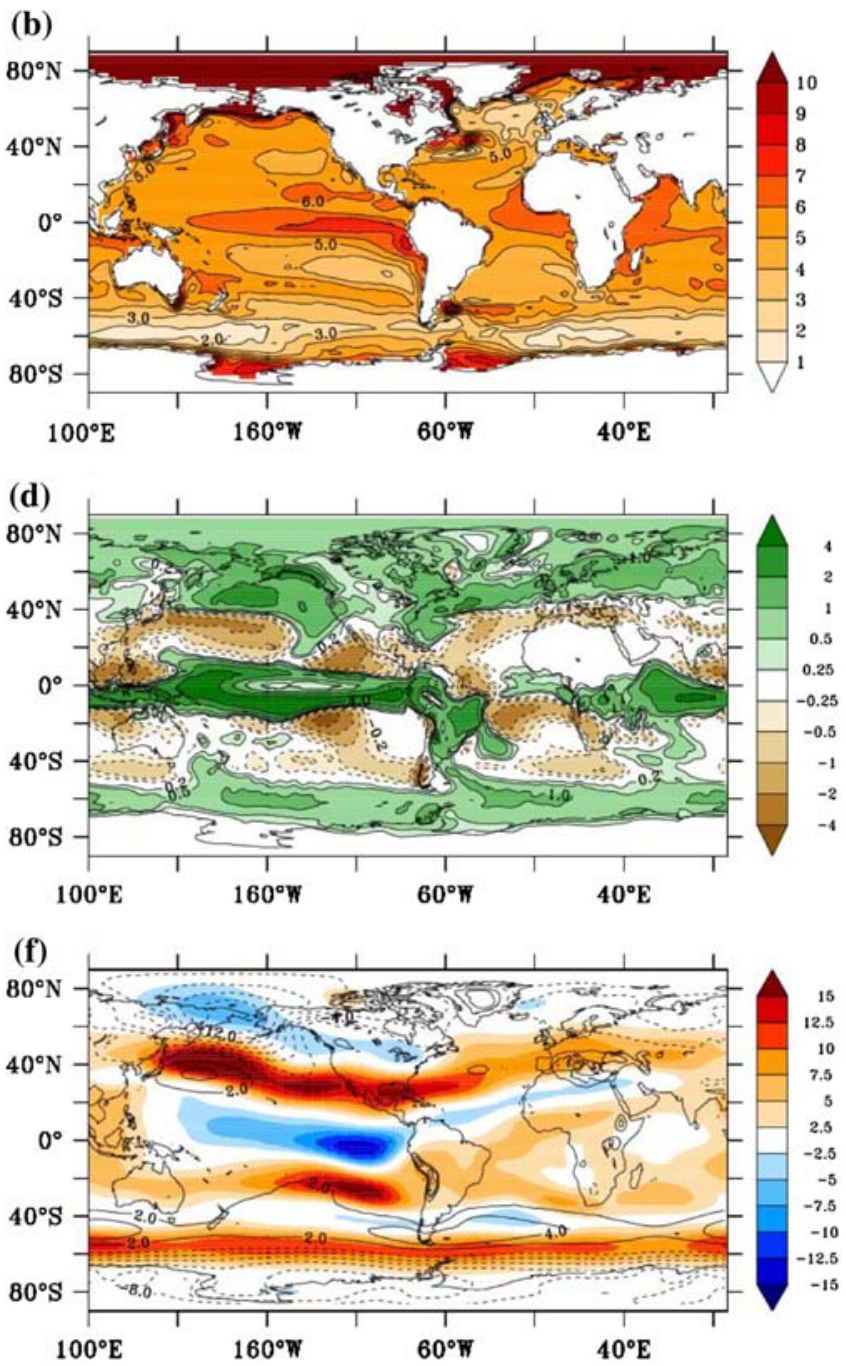

Fig. 8 Composite maps of NEUTRAL of (left) surface temperature and precipitation and (right) U200 and SLP. Shown are a, b 20C, c, d A1B $22 \mathrm{C}-20 \mathrm{C}$ and e, $\mathbf{f} 4 \times \mathrm{CO}_{2}-\mathrm{CTRL}$. Contour intervals are the same as in Figs. 1 and 2. Only values exceeding 95\% significance are shown

from a random sample. In the $20 \mathrm{C}$ runs significant values are found for the Nnio3.4 index above $2.5^{\circ} \mathrm{C}$. This illustrates that ENSO even with moderate amplitudes (i.e. $1.5^{\circ} \mathrm{C}$ ) become significantly more influential on the NAE zonal wind in the A1B scenario than in the present climate. Thus, for given ENSO amplitude, the ENSO teleconnections associated with the UI are different for the present and future climate, respectively. This implies that other processes with a presumably longer timescale (Sterl et al. 2007) are influential on the ENSO teleconnection in the future climate projections. As we have shown in section 3 there is a considerable "El-Nino like" change in the mean state in the subtropical North Pacific and North Atlantic. From that and the results in this subsection we therefore suggest that the changing amplitude of ENSO and the changing mean state in concert triggers the ENSO teleconnections in the NAE region.
As demonstrated by Ting et al. (1996) variations of the UI explains a significant fraction of the stationary wave variability in the NAE region. Further, stationary wave trains are a key mechanism for the extra-tropical response to tropical SST anomalies and stationary wave activity is suggested to serve an upstream precondition for a link between ENSO and the NAE region (Fraedrich 1994). From this and Fig. 9 it is expected that the alteration of the zonal wind by the El Niño-like changes of the mean climate increasingly contribute to the wintertime stationary wave variability in the NAE region.

Stationary waves are here defined as the deviation from the zonal mean. Figure 10 shows the winter mean of the stationary wave height for the 20C, A1B $22 \mathrm{C}$ and $4 \times \mathrm{CO}_{2}$ runs. For the NEUTRAL 20C case (Fig. 10a) a stationary wave with wavenumber two is present, with negative values in the West Pacific and Northeast America and positive 


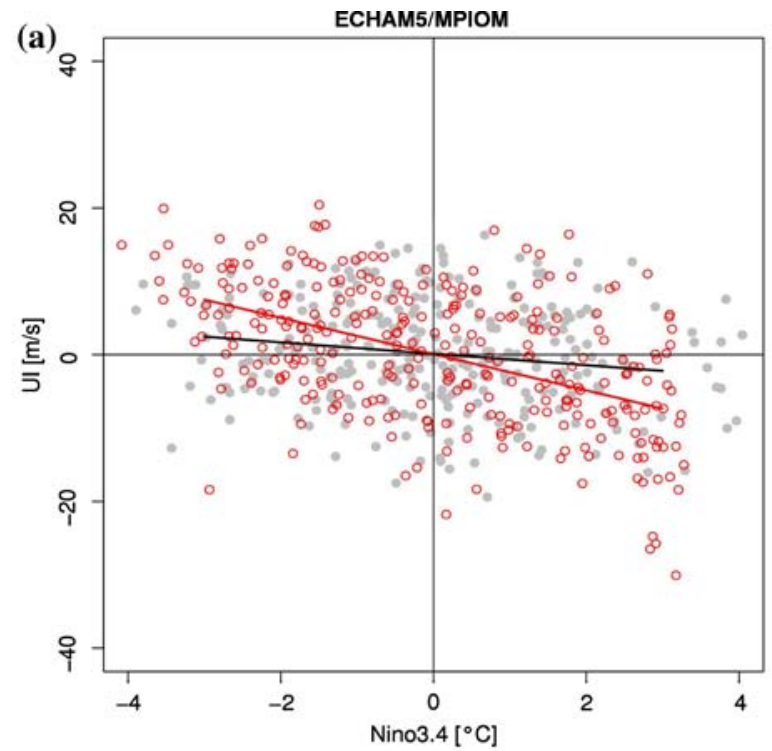

(b)

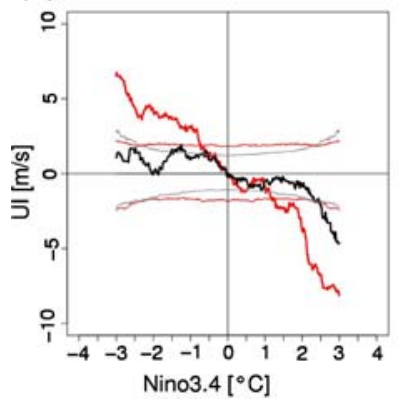

(c)

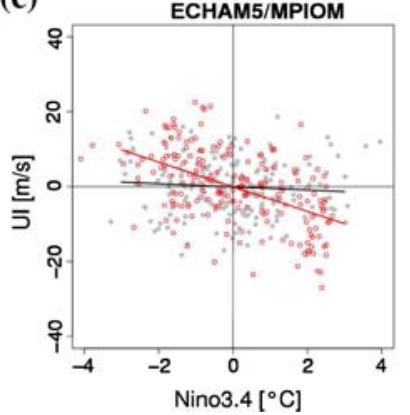

Fig. 9 Scatter plots of the zonal wind index (UI) versus the Nino3.4 index for a $20 \mathrm{C}$ and $\mathrm{A} 1 \mathrm{~B} 22 \mathrm{C}$ and $\mathbf{c} \mathrm{CTRL}$ and $4 \times \mathrm{CO}_{2}$. Present climate runs (20C and CTRL) are shown in grey and future climate projection (A1B $22 \mathrm{C}$ and $4 \times \mathrm{CO}_{2}$ ) are shown in red. The lines indicate linear regressions. The UI is defined as the difference of the zonal wind averaged in the NAE region $\left(80-0^{\circ} \mathrm{W}\right)$ for $50-60^{\circ} \mathrm{N}$ minus $40-30^{\circ} \mathrm{N}$. b Composites of the UI as a function of the amplitude of the Nino3.4 index for the 20C runs (grey) and the A1B runs (red). Thin lines indicate 95\% significance levels. Composites are performed for every Nino3.4 amplitude within a bin of size $\pm 0.75^{\circ} \mathrm{C}$

values over the Rocky Mountains and Eurasia, similar to the observed pattern. The amplitudes, however, are smaller than in observations and in atmospheric modeling studies using ECHAM5 forced with observed SST and sea ice (Manzini et al. 2006; Roeckner et al. 2006). Differences relative to the $20 \mathrm{C}$ winter climate for the A1B $22 \mathrm{C}$ and $4 \times \mathrm{CO}_{2}$ runs (Fig. 10c, e) reveal a northeastward elongation of the North Pacific trough and northward displacement of the ridge over the Rocky Mountains. Moreover, the trough over the eastern coast of North America is shifted to the east and the Eurasian ridge system is amplified in its southern (Mediterranean region) and eastern part. The negative anomaly emerging over the southern US can be attributed to the El Niño-like change of the future mean state and is consistent with other analyses describing the stationary wave response to climate change (e.g. Joseph et al. 2004). For comparison the winter mean stationary wave height is also shown in Fig. 10 (right panels). The structures and amplitudes of the winter mean wave height are similar to the NEUTRAL cases.

The composite maps of ENSO+ and ENSO- are shown in Fig. 11. For 20C (Fig. 11a, b) the wave height composite largely resembles that of the MSLP and is consistent with observational and modeling analyses (Hoerling et al. 1997; Manzini et al. 2006). For ENSO+ in 20C the composites reveal an eastward extension of the Northwest Pacific trough and northward shift of the North American ridge, similar to the time-mean response obtained in the NEUTRAL case (cf., Fig. 11c, e). This similarity suggests that the extratropical response found in our climate change experiments is largely triggered by the El Niño-like change in the SST pattern. For ENSO- the wave height anomalies appear almost in quadrature to ENSO+. In the climate change experiments, eastward shifts of the wave anomalies are discernible, particularly for the $4 \times \mathrm{CO}_{2}$ runs. For ENSO+ the Pacific dipole has a pronounced eastward extension compared to the 20C run (Fig. 11c, e). Over the North Atlantic the ENSO+ composites reveal a pronounced northsouth orientation, particularly in the $4 \times \mathrm{CO}_{2}$ experiment, in striking similarity to the negative phase of the NAO. In the North Atlantic region the wave height anomalies for ENSO- show a slight tendency towards a positive NAOlike response, but they have a smaller zonal elongation as for ENSO+ events and much weaker amplitude.

These results show that the GHG triggered NAO-like changes in the NAE region associated with ENSO in ECHAM5/MPI-OM are related to changes in the mean zonal wind (i.e. the UI) and stationary wave activity. The composites of the stationary eddy height (Fig. 11) show asymmetric patterns for ENSO+ and ENSO-, respectively, with the negative phase of the NAO-like anomalies clearly dominating in the ENSO+ cases. This is in line with results by Müller and Roeckner (2006), where it is shown that the correlation between the NAO and ENSO is significantly increased in future climate projections. A positive NAO is followed by ENSO- events and negative NAO is likely associated with ENSO+ events.

\section{Summary and conclusions}

The climate simulations performed with ECHAM5/MPIOM for the IPCC AR4 are used to examine ENSO teleconnection in projections of the future climate. The model simulations use atmospheric concentrations fixed at preindustrial levels (CTRL), observed concentrations in the twentieth century simulations (20C) and IPCC SRES A1B 
Fig. 10 NEUTRAL cases (left) and winter (DJF) mean of the stationary eddy height at $500 \mathrm{hPa}$ (right) for a, b $20 \mathrm{C}$, c, d A1B $22 \mathrm{C}-20 \mathrm{C}$ and $\mathbf{e}, \mathbf{f}$ $4 \times \mathrm{CO}_{2}-\mathrm{CTRL}$. Contour intervals are a, b $40 \mathrm{~m}$ and b-e $20 \mathrm{~m}$

Fig. 11 Same as Fig. 5 but for the DJF stationary eddy height at $500 \mathrm{hPa}$. Contour intervals are $10 \mathrm{~m}$ (a)
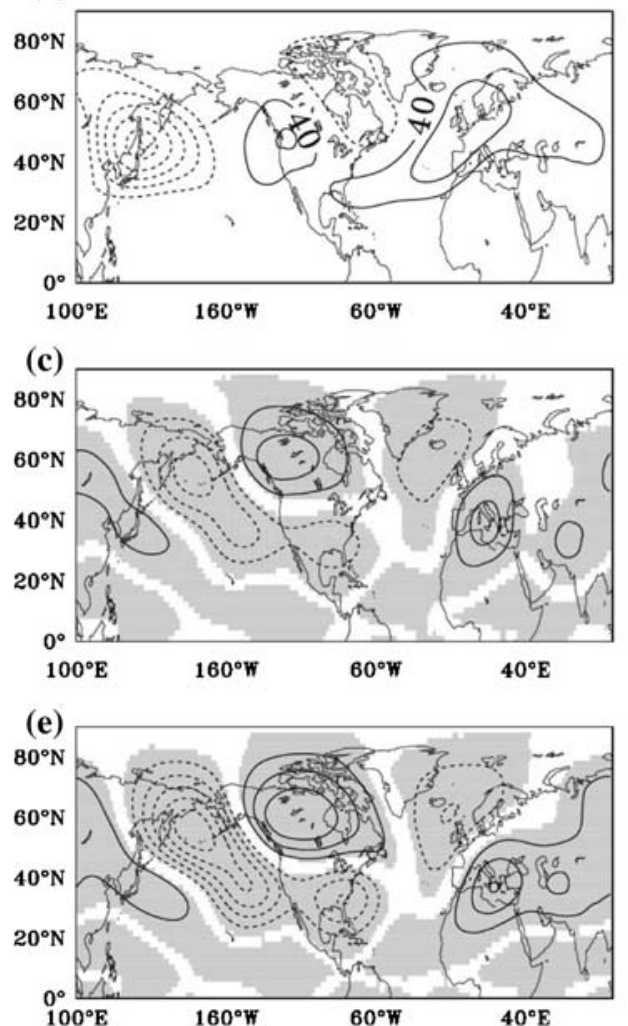

(b)

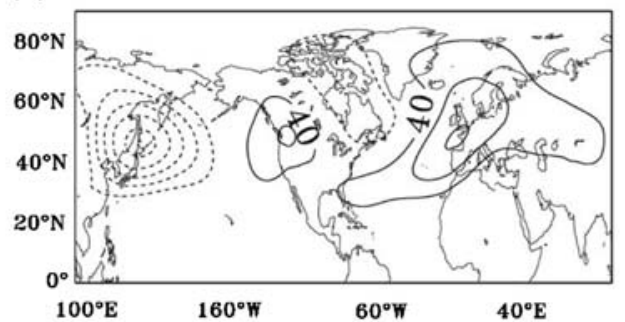

(d)

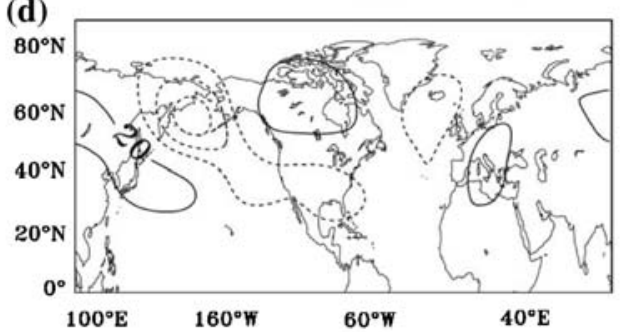

(f)

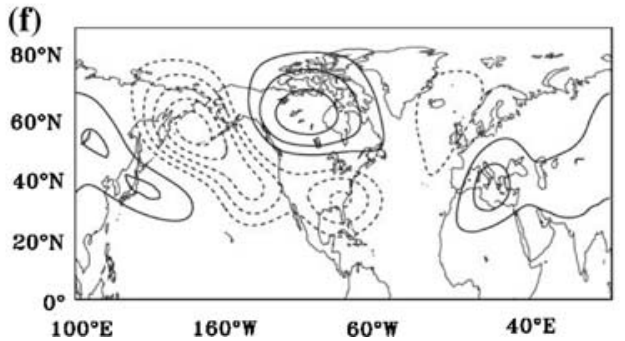

(b)

(a)
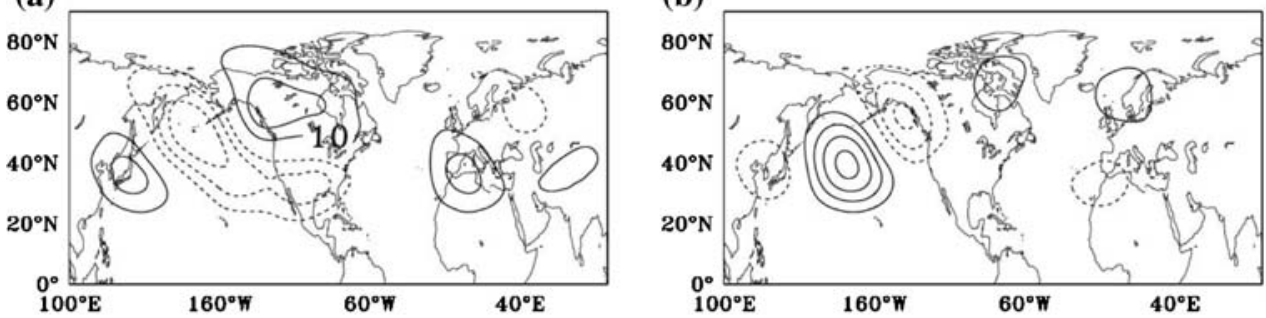

(c)

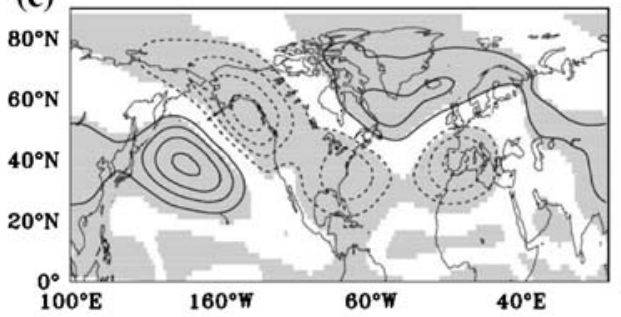

(d)

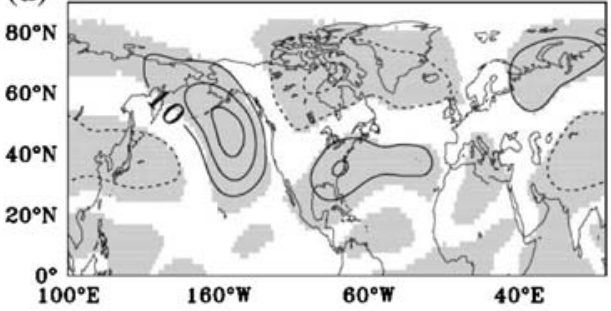

(e)

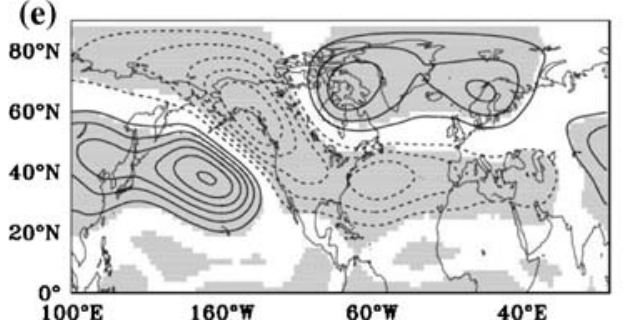

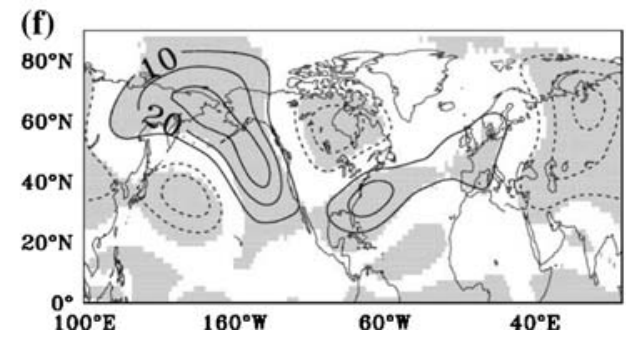


stabilization runs with atmospheric concentrations fixed at their year 2100 level (A1B 22C). Further, an idealized climate change experiment with an annual increase of atmospheric $\mathrm{CO}_{2}$ by $1 \%$ until $\mathrm{CO}_{2}$ quadrupling is used $\left(4 \times \mathrm{CO}_{2}\right)$.

The future climate projections of ECHAM5/MPI-OM reveal a marked change in the ENSO teleconnections. First, the model simulations of $\mathrm{A} 1 \mathrm{~B} 22 \mathrm{C}$ and $4 \times \mathrm{CO}_{2}$ show a substantial increase in the mean SST in the tropical Pacific associated with an eastward extension of the maximum precipitation. The winter mean conditions of different atmospheric parameters show an El Niño-like response from the tropical Pacific to the extra-tropics, shared by many models of the IPCC AR4. The tropical circulation is altered via a reduction of the Walker circulation and anomalous Hadley circulation in the eastern Pacific, consistent with changes found during El Niño conditions (see Wang 2005). The sub-tropical jet is increased and the midlatitude mean circulation exhibits a pronounced eastward extension in the Pacific North American (PNA) region and a strong zonalisation of the mean flow over the North Atlantic/European (NAE) region. The changes in the winter mean climate are largely similar to the changes associated with periods when the ENSO activity is weak. This implies that the El Niño-like change in the tropical Pacific is not due to changes in the distribution of ENSO events.

Composites of various atmospheric parameters for positive and negative ENSO events exhibit a pronounced eastward shift of the teleconnection patterns in the future climate projections. Large-scale atmospheric circulation patterns over the PNA region appear to be shifted further northeastward. Climate parameters such as MSLP and precipitation also show an eastward shift. In the NAE region composites of MSLP and zonal wind reveal prevailing negative NAO-like anomalies for El Niño events. Further an examination of planetary waves indicates an increasing activity of tropically forced stationary waves
Fig. 12 Same as Fig. 9a but for 100 year simulation of the a CGCM3.1 (L47), b

FGOALS_g1.0, c CCSM3, d GFDL-CM2.0, e MRICGCM2_3_2 and f ECHAM5/ MPIOM. a-c Models with decreasing ENSO amplitude and $\mathbf{d}-\mathbf{e}$ models with increasing ENSO amplitude (e.g. see Meehl and Teng 2007).

Numbers indicate correlation coefficient between UI and ElNino3.4, here equal to $R^{2}$ (e.g. see Wilks 2006). Significant values are given in bold and 95\% confidence intervals in brackets
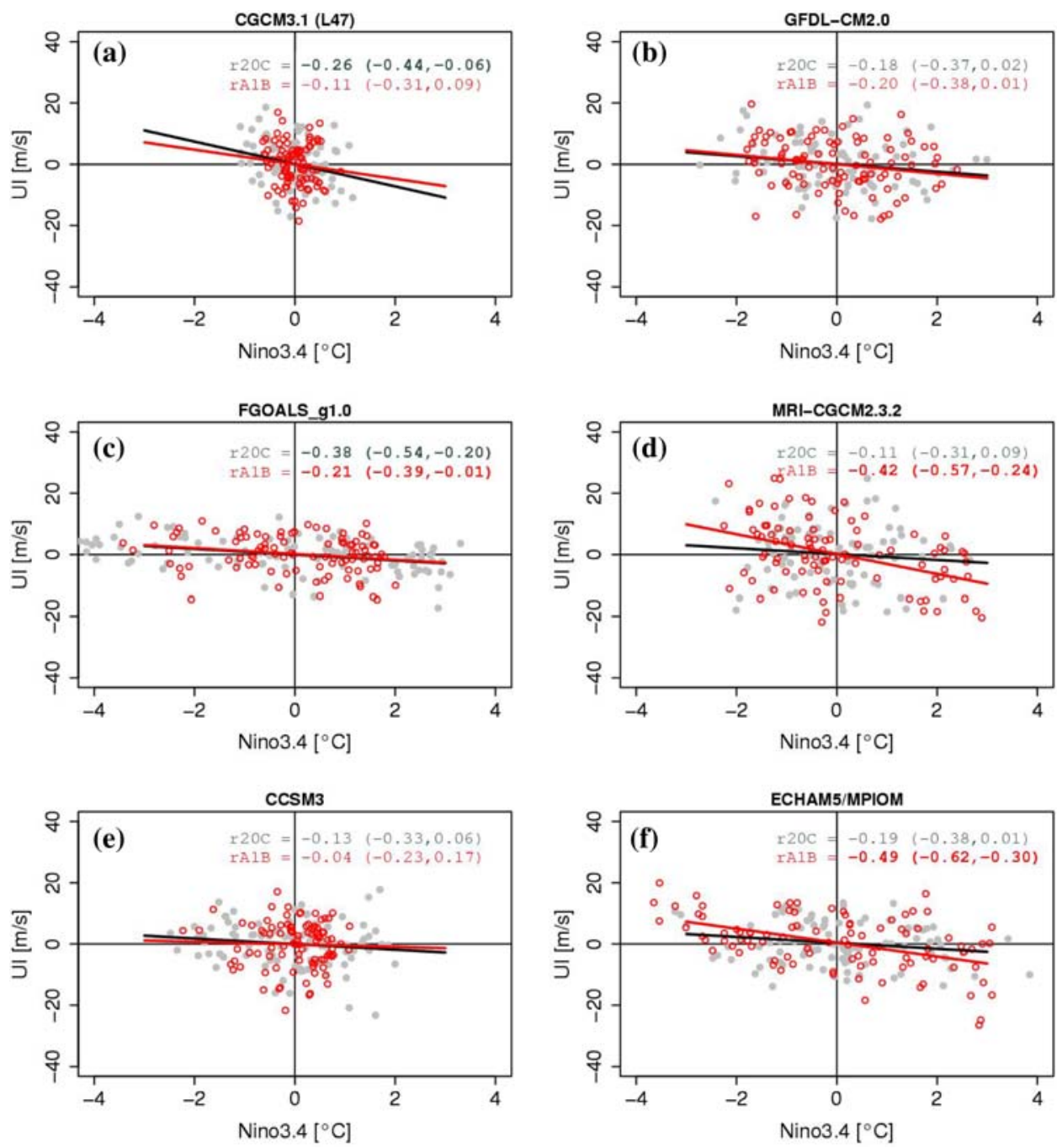
over the North Atlantic. During the positive and negative phase of ENSO the stationary waves increasingly appear in NAO-like structures and are in line with the findings in Müller and Roeckner (2006).

Our analysis indicates a close correspondence between the changes of the mean state and the teleconnections associated with ENSO+ in ECHAM5/MPI-OM. Therefore, it seems worthwhile to investigate this relationship in the IPCC AR4 model runs which show a remarkable spread in the ENSO response to global warming (e.g. van Oldenborgh et al. 2005; Guilyardi 2006). Though the models show consistent changes in the mean state of the upper troposphere in the PNA region, there is a difference in the changes of ENSO teleconnections depending on the sign of the ENSO response, as recently pointed out by Meehl and Teng (2007). In their analysis they show that within the models with increasing ENSO amplitudes in the warmer climate (and the ECHAM5/MPI-OM runs are among the models with the largest increase in ENSO amplitude) the teleconnection patterns over the PNA region appear similar to the changes of the mean state. For the models with deceasing ENSO amplitude, however, the patterns are not congruent. It is argued that though the changes of the ENSO amplitude largely trigger changes of the teleconnection in the PNA region, the changes of the mean-state provide an additional contribution. This is in line with our results for ECHAM5/MPI-OM where a large contribution of the mean state on to the ENSO teleconnection in the NAE region is found, in addition to the strength of ENSO (see Fig. 9b).

We have shown (Fig. 9) that the upper level zonal wind variations [in terms of a zonal wind index (UI)] defined over the NAE region is increasingly affected by ENSO in a warmer climate in the ECHAM5/MPI-OM runs. In Fig. 12 we show the UI in relation to the Nino3.4 index for an ensemble of climate models from the IPCC AR4. This ensemble is divided into subsets of models characterized by an increasing and decreasing ENSO amplitude in the corresponding scenarios, respectively (see also Meehl and Teng 2007). Among those models with a decrease of ENSO amplitude there is no change or a reduction in the relationship between UI and Nino3.4 (though the significance levels indicate that a robust interpretation is not possible here). For those models with increasing ENSO amplitude two out of three models (MRI-CGCM, ECHAM5/MPI-OM) show an increase of the correlation between ENSO and UI, though the 95\% confidence intervals overlap. The third model (GFDLCM2.0) shows no significant changes. Despite this brief and certainly not complete analysis this figure indicates that the mechanism for an intensification of the ENSO teleconnection in the NAE region described in the present study can also be drawn from other IPCC AR4 models, particularly those models with increasing ENSO amplitude.

The results underline the need for a robust estimation of future ENSO variability and its impact on the climate variability in the NAE region. Moreover, since the wintertime extra-tropical climate variability shows a large sensitivity to small variations of the mean zonal flow (even internal atmospheric variations of the mean zonal wind are suggested to explain a large fraction of the stationary wave activity; e.g. Ting et al. 1996), also the robust estimation of the zonal wind in these regions is of primary concern for the mechanism described here.

In the present study the increasing ENSO teleconnection in the NAE region is explained by a stronger sensitivity between the mean zonal wind and the stationary wave activity in the warmer climate. Diagnostic studies, however, show distinct sensitivity of both stationary and transient eddy activity to ENSO (Fraedrich 1994; Merkel and Latif 2002). Hence to better understand and fully describe the mechanism driving the ENSO impact on the NAE climate variability in a future climate a consideration of the complete wave activity including transient and stationary waves and their relationship to changes of the mean state would be required.

Finally, it is of particular interest how other climate variables in the NAE region are affected. For example since there is strong evidence for an influence of SST on the Northern Hemisphere winter stratosphere in the current climate (Manzini et al. 2006) altered transient and stationary waves may further modify stratospheric circulation in the Northern Hemisphere in the future climate. Further with an increasing influence of ENSO on the NAE region changes in the climate variability near the surface are suspected. However, our composites show only small changes of surface temperature and precipitation related to ENSO. Other analysis techniques may be more appropriate, e.g. monitoring changes in the extreme values associated with ENSO. This could be more relevant since extreme weather events are expected to occur more frequently in the future climate and increased ENSO variability might further modify these extremes.

Acknowledgments We thank Traute Crüger and Holger Pohlmann for helpful comments on the original manuscript. The suggestions made by two anonymous reviewers substantially improved the quality of the manuscript. This research was financed in part by the German Ministery for Education and Research (BMBF) under the DEKLIM Project and by the European Community under the ENSEMBLES Project. Additional support was given by the EUProject DYNAMITE. The simulations were performed on the NEC SX-6 supercomputer installed at the German Climate Computing Centre (DKRZ) in Hamburg. We thank the R development Core Team (2006) for providing the software $\mathrm{R}$. The authors further wish to acknowledge use of the Ferret program for analysis and graphics in this paper (Information is available at http://ferret.pmel.noaa.gov/Ferret/) 


\section{References}

Achutarao K, Sperber KR (2006) ENSO simulation in coupled oceanatmosphere models: are the current models better. Clim Dyn 27:1-15

Bengtsson L, Hodges KI, Roeckner E (2006) Storm tracks and climate change. J Clim 19:3518-3543

Boer GJ, Flato F, Ramsden D (2000) A transient climate change simulation with greenhouse gas and aerosol forcing: projected climate for the 21 st century. Clim Dyn 16:427-450

Branstator G (1984) The relationship between zonal mean flow and quasi-stationary waves in the mid-troposphere. J Atmos Sci $41: 2163-2178$

Branstator G (2002) Circumpolar teleconnections, the jet stream waveguide and the North Atlantic oscillation. J Clim 15:18931910

BrönimannS, Xoplaki E, Casty C, Pauling A, Luterbach J (2007) ENSO influence on Europe during the last centuries. Clim Dyn 28:181-197

Chapman WL, Walsh JE (2007) Simulations of Arctic temperature and pressure by global coupled models. J Clim 20:609-632

Collins M (2000) Understanding uncertainties in the response of ENSO to greenhouse warming. Geophys Res Lett 27:35093513

Collins M et al (2005) El Niño- or La Niña-like climate change? Clim Dyn 24:89-104

Dai A, Wigley L, Boville BA, Kiehl JT, Buja LE (2001) Climate of the twentieth and twenty-first century simulated by the NCAR climate system Model. J Clim 14:485-519

DeWeaver E, Nigam S (2000a) Do stationary waves drive the zonalmean jet anomalies of the northern winter. J Clim 13:2160-2176

DeWeaver E, Nigam S (2000b) Zonal-Eddy dynamics of the North Atlantic oscillation. J Clim 13:3893-3914

Fraedrich K (1994) ENSO impact on Europe? A review. Tellus 46A:541-552

Fraedrich K, Müller K (1992) Climate anomalies in Europe associated with ENSO extremes. Int J Climatol 12:25-31

Gadgil S, Joseph PV, Joshi NV (1984) Ocean-atmosphere coupling over mosoon regions. Nature 312:141-143

Guilyardi E (2006) El Niño-mean state-seasonal cycle interactions in a multi-model ensemble. Clim Dyn 26(4):329-348

Hoerling MP, Kumar A (1995) Zonal flow-stationary wave relationship during El Niño: implication for seasonal forecasting. J Clim 8:1838-1852

Hoerling MP, Kumar A, Zhang M (1997) El Niño, La Niña and the nonlinearity of their teleconnection. J Clim 10:1769-1786

Joseph R, Ting M, Kushner PJ (2004) The global stationary wave response to climate change in a coupled GCM. J Clim 17:540-556

Jungclaus JH, Botzet M, Haak H, Keenlyside N, Luo JJ, Latif M, Marotzke J, Mikolajewicz U, Roeckner E (2006) Ocean circulation and tropical variability in the coupled model ECHAM5/MPI-OM. J Clim 19:3952-3972

Keenlyside N, Latif M, Jungclaus J, Botzet M, Schuzweida U (2004) A coupled method for initializing ENSO forecasts using SST data. Tellus 57A:340-356

Knutson TR, Manabe S (1995) Time-mean response over the tropical Pacific due to increased $\mathrm{CO}_{2}$ in a coupled ocean-atmosphere model. J Clim 8:2181-2199

Lin H, Derome J, Brunet G (2005) Tropical Pacific link to the two dominant patterns of atmospheric variability. Geophys Res Lett 32. doi:10.1029/2004GL021495

Manzini E, Giorgetta MA, Esch M, Kornblueh L, Roeckner E (2006) The influence of sea surface temperatures on the Northern winter stratosphere: ensemble simulations with the MAECHAM5 model. J Clim 19:3863-3881
Marsland SJ, Haak H, Jungclaus JH, Latif M, Röske F (2003) The Max Planck Institute global ocean/sea ice model with orthogonal curvilinear coordinates. Ocean Model 5:91-127

Mathieu PP, Sutton RT, Dong B, Collins M (2004) Predictability of winter climate over the North Atlantic European region during ENSO events. J Clim 17:1953-1975

Meehl GA, Teng H (2007) Multi-model changes in El Niño teleconnections over North America. Clim Dyn. doi: 10.1007/s00382-007-0268-3

Meehl GA, Branstator GW, Washington WM (1993) Tropical Pacific interannual variability and $\mathrm{CO}_{2}$ climate change. J Clim 6:42-63

Meehl GA, Teng H, Branstator G (2006) Future changes of El Niño in two global coupled climate models. Clim Dyn 26:549-566

Merkel U (2003) ENSO Teleconnection in high resolution AGCM experiments. PhD Thesis, Max Planck Institute for Meteorology, Hamburg, pp 98

Merkel U, Latif M (2002) A high resolution AGCM study of the El Niño impact on the North Atlantic/European sector. Geophys Res Lett 29:1-4

Merryfield W (2006) Changes to ENSO under $\mathrm{CO}_{2}$ doubling in the IPCC AR4 coupled climate models. J Clim 19:4009-4027

Müller WA, Roeckner E (2006) ENSO impact on mid-latitude circulation patterns in future climate change projections. Geophys Res Lett 11. doi: 10.1029/2005GL025032

Nigam S, Lindzen RS (1989) The sensitivity of stationary waves to variations in the basic state zonal flow. J Atmos Sci 46:1746-1768

Philip S, van Oldenborgh GJ (2006) Shifts in ENSO coupling processes under global warming. Geophys Res Lett 33. doi: 10.1029/2006GL026196

R Development Core Team (2006) R: A language and environment for statistical computing. R Foundation for Statistical Computing, Vienna, Austria. ISBN 3-900051-07-0, URL http://www. R-project.org

Roeckner E et al (2003) The atmosphere general circulation model ECHAM5, part I: model description. Max-Planck Institute for Meteorology, $127 \mathrm{pp}$

Roeckner E, Brokopf R, Esch M, Giorgetta M, Hagemann S, Kornblueh L, Manzini E, Schlese U, Schulzweida U (2006) Sensitivity of simulated climate to horizontal and vertical resolution in the ECHAM5 atmosphere model. J Clim 19:3771-3791

Sterl A, van Oldenborgh GJ, Hazeleger W, Burgers G (2007) On the robustness of ENSO teleconnections. Clim Dyn. doi: 10.1007/s00382-007-0251-z

Ting M, Hoerling MP, Xu T, Kumar A (1996) Northern hemisphere teleconnection patterns during extreme phases of the zonal-mean circulation. J Clim 9:2614-2633

Timmermann A, Oberhuber O, Bacher A, Esch M, Latif M, Roeckner E (1999) Increased El Niño frequency in a climate model forced by greenhouse warming. Nature 398:694-697

Trenberth KE et al (1998) Progress during TOGA in understanding and modelling global teleconnections associated with tropical sea surface temperature. J Geophys Res 03:14291-14324

Valcke S, Caubel A, Declat D, Terray L (2004) OASIS Ocean Atmosphere Sea Ice Soil user's guide. Technical report TR/ CMGC/03/69. CERFACS, Toulouse, France

van Oldenborgh GJ, Burgers G, Klein Tank A (2000), On the El Niño teleconnection to spring precipitation in Europe. Int $\mathrm{J}$ Clim 20:565-574

van Oldenborgh GJ, Philip S, Collins M (2005) El Nino in a changing climate: a multi-model study. Ocean Sci 1:81-95

Van Ulden AP, van Oldenborgh GJ (2006) Large-scale atmospheric circulation biases and changes in global climate model simulations and their importance for climate change in Central Europe. Atmos Chem Phys 6:863-881 
Vecchi GA, Soden BJ (2007) Global warming and the weakening of the tropical circulation. J Clim (accepted)

Wang C (2005) ENSO, Atlantic climate variability, and the Walker and Hadley circulation. In: Diaz HF, Bradley RS (eds) The Hadley circulation: Present, past and future, pp 173-202
Wilks DS (2006) Statistical methods in the atmospheric sciences. International Geophysics Series, vol 91. Academic Press, New York, p 627

Yeh SW, Kirtman BP (2007) ENSO amplitude changes due to climate change projections in different coupled models. J Clim 20:203-217 